Florida International University

FIU Digital Commons

6-25-2019

\title{
The Effect of Methylphenidate on Associative Learning Among Youth with Attention-Deficit/Hyperactivity Disorder
}

Amy R. Altszuler

Florida International University, aaltszul@fiu.edu

Follow this and additional works at: https://digitalcommons.fiu.edu/etd

Part of the Child Psychology Commons, and the Clinical Psychology Commons

\section{Recommended Citation}

Altszuler, Amy R., "The Effect of Methylphenidate on Associative Learning Among Youth with AttentionDeficit/Hyperactivity Disorder" (2019). FIU Electronic Theses and Dissertations. 4207.

https://digitalcommons.fiu.edu/etd/4207

This work is brought to you for free and open access by the University Graduate School at FIU Digital Commons. It has been accepted for inclusion in FIU Electronic Theses and Dissertations by an authorized administrator of FIU Digital Commons. For more information, please contact dcc@fiu.edu. 


\section{FLORIDA INTERNATIONAL UNIVERSITY}

Miami, Florida

\author{
A dissertation submitted in partial fulfillment of the \\ requirements for the degree of \\ DOCTOR OF PHILOSOPHY \\ in \\ PSYCHOLOGY
}

by

Amy R. Altszuler

2019 
To: Dean Michael R. Heithaus

College of Arts, Sciences and Education

This dissertation, written by Amy R. Altszuler, and entitled The Effect of Methylphenidate on Associative Learning among Youth with Attention-Deficit/Hyperactivity Disorder, having been approved in respect to style and intellectual content, is referred to you for judgement.

We have read this dissertation and recommend that it be approved.

Daniel Waschbusch

Joseph Raiker

Aaron Mattfeld

$\frac{\text { Andy Pham }}{\text { William E. Pelham, Jr., Major Professor }}$

Date of Defense: June 25, 2019

The dissertation of Amy R. Altszuler is approved.

$\frac{\text { Andy Pham }}{\text { William E. Pelham, Jr., Major Professor }}$ 


\section{ABSTRACT OF THE DISSERTATION \\ THE EFFECT OF METHYLPHENIDATE ON ASSOCIATIVE LEARNING AMONG YOUTH WITH ATTENTION-DEFICIT/HYPERACTIVITY DISORDER \\ by}

Amy R. Altszuler

Florida International University, 2019

Miami, Florida

Professor William E. Pelham, Jr., Major Professor

Despite strong evidence supporting the short-term efficacy of interventions for youth with Attention-Deficit/Hyperactivity Disorder (ADHD), and despite the fact that the majority of youth with ADHD receive treatment for the disorder at some point over the course of childhood, the long-term prognosis for individuals with ADHD remains poor. One potential explanation for the gap between short-term efficacy and long-term outcomes is that the most common intervention for youth with ADHD, stimulant medication, paradoxically undermines children's abilities to learn from contingencies through their action on the dopaminergic system. The dynamic dopamine theory posits that by increasing levels of dopamine, stimulant medication enhances reward-based learning but prevents phasic dips in dopamine necessary for punishment-based learning to occur. The current study explored the hypothesis that stimulant medication undermines punishment-based learning among school-aged youth diagnosed with ADHD using an associative learning task. The study used a 4 (stimulant medication dose: placebo, low, moderate, high) x 2 (trial type: reward, punishment) x 2 (punishment condition: regular, enhanced) design to evaluate children's ability to learn stimuli-category associations following reward and punishment. On reward-based trials, participants earned points 
following correct associations and received no feedback following incorrect associations. On punishment trials, participants lost points (20 in the regular condition, 100 in the enhanced condition) following incorrect associations and received no feedback following correct associations. Results indicated that there was no significant main effect of medication on children's associative learning. Rather, children demonstrated better overall performance in response to rewards regardless of medication condition. Children performed worse when they received the enhanced punishment condition, an effect that was moderated by higher doses of medication. Results indicate that other factors, aside from dopamine levels, likely contribute to associative learning among youth with ADHD. Specifically, the punishment to reward ratio is likely an important factor that should be considered when designing interventions for youth with ADHD. 
CHAPTER

PAGE

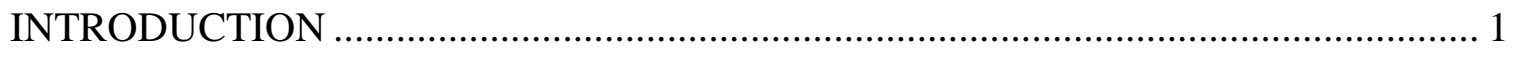

Research Objectives and Hypotheses ..................................................................... 7

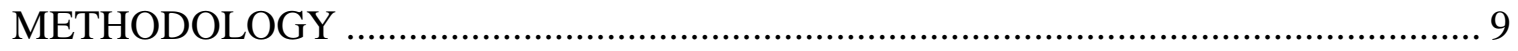

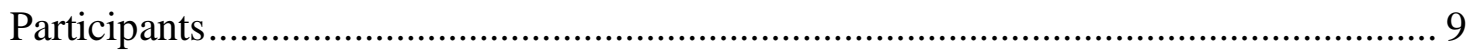

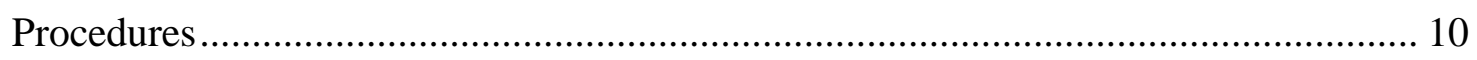

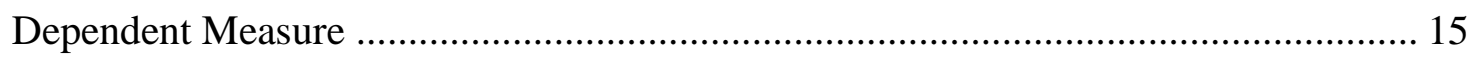

Analyses and Handling of Missing Data ............................................................. 15

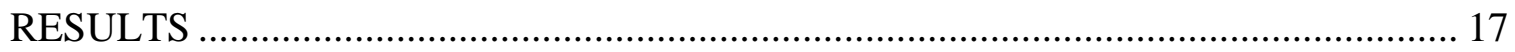

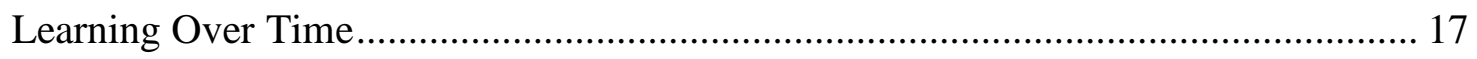

Direct Effects of Study Manipulations ………………………………………….... 17

Interaction of Medication, Trial Type, and Punishment .......................................... 18

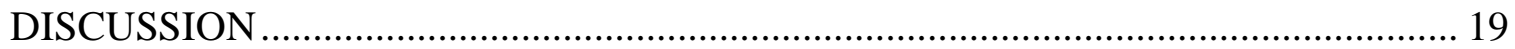

Lack of Main Effects of Medication ..................................................................... 19

Differences in Punishment- and Reward-Based Learning ......................................... 21

Differences by Punishment Condition ................................................................... 24

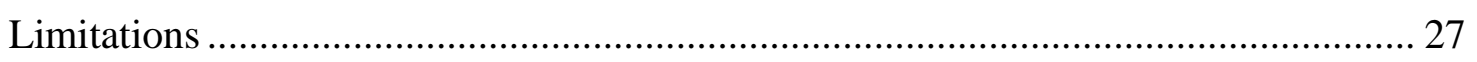

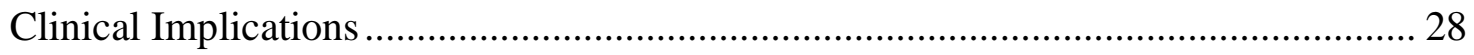

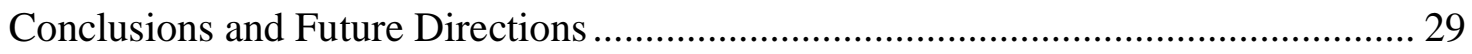

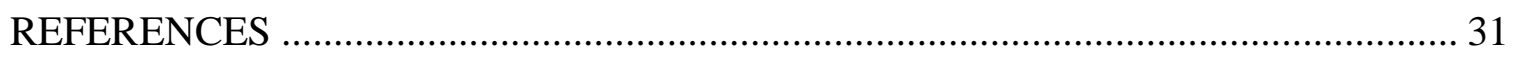

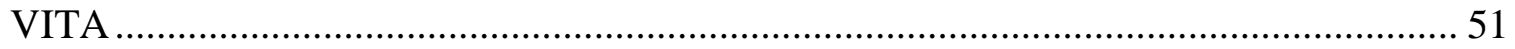




\section{LIST OF TABLES}

TABLE

PAGE

1. Sample Characteristics ...................................................43

2. Sample Participant Testing Schedule.......................................44

3. Task Structure by Trial Type and Punishment Condition.........................45

4. Raw Means and Standard Deviations for Dependent Measures .......................46

5. Results of Multilevel Model for Task Performance ..............................47 


\section{LIST OF FIGURES}

FIGURE

PAGE

1. Task Feedback by Trial Type and Punishment Condition ...........................48

2. Task Learning by Punishment Condition and Trial Type..............................49

3. Task Performance by Trial Type, Punishment Condition, and Medication Dose......50 


\section{INTRODUCTION}

Attention-Deficit/Hyperactivity Disorder (ADHD) is a chronic

neurodevelopmental disorder affecting approximately $10 \%$ of children and adolescents in the U.S. (Danielson, Bitsko, et al., 2018). The core symptoms of ADHD - inattention, hyperactivity, and impulsivity, lead to significant impairment across domains of daily life functioning, including home, school, and peer settings (Barkley, 2015; Fabiano et al., 2006). For the majority of individuals diagnosed with ADHD, symptoms continue to cause significant educational, financial, occupational and interpersonal problems in young adulthood (Altszuler et al., 2015; Barkley, Murphy, \& Fischer, 2008; Gordon \& Fabiano, 2019; Hechtman et al., 2016; Kuriyan et al., 2013), and for a subset of individuals ADHD develops into more serious impairments during adolescence and young adulthood, including substance abuse and criminality (Merrill et al., 2019; Molina \& Pelham, 2014; Sibley et al., 2011). The prevalence and persistence of ADHD-related problems across several areas of functioning places a large economic burden on society, with recent cost estimates in the U.S. ranging from \$143 - \$266 billion annually (Doshi et al., 2012). Understanding how to best intervene with youth with ADHD to reduce lifelong impairment associated with the disorder is therefore not only a matter of critical importance to individuals with ADHD and their families, but also a major public health concern.

Attention-Deficit/Hyperactivity Disorder remains a prevalent and costly problem despite decades of research supporting the significant acute benefits of interventions for the disorder, including stimulant medication, behavioral interventions (e.g., behavioral 
parent training, behavioral classroom management) and their combination (Evans, Owens, \& Bunford, 2014; Evans, Owens, Wymbs, \& Ray, 2017; Fabiano et al., 2009; Macphee, Altszuler, Merrill, \& Pelham, 2017; Pelham \& Fabiano, 2008; Pliszka, 2007; Wolraich et al., 2011). Importantly, whereas stimulant medication is the most common of these treatments, with $90 \%$ of children with the disorder receiving stimulant treatment at some point in their lifetime (Danielson, Visser, Chronis-Tuscano, \& DuPaul, 2018), no long-term benefits associated with stimulant medication has been documented in the literature. Stimulant effects are only apparent as long as the medication has a pharmacological effect (4 to 12 hours depending on the formulation; Pelham et al., 2001). Further, there do not appear to be any residual benefits associated with taking medication. In the Multimodal Treatment Study of ADHD (MTA), the largest longitudinal study of ADHD treatment to date, children who received stimulant medication outperformed those who received behavioral treatment alone at the initial 14-month assessment (MTA Cooperative Group, 1999), but by the 24-month assessment the benefit of medication over behavioral treatment decreased by 50\% (MTA Cooperative Group, 2004) and by the 36-month assessment there was no measurable benefit of medication over behavioral intervention (Jensen, Arnold, Swanson, Vitiello, \& Abikoff, 2007).

It is surprising that medication does not produce long-term benefits, as it has large acute effects on domains that would be expected to lead to improvements in long-term functioning, such as on-task behavior, compliance, and academic productivity (Chronis, Pelham, Gnagy, Roberts, \& Aronoff, 2003; Fabiano et al., 2007; Greenhill, 2002; Kortekaas-Rijlaarsdam, Luman, Sonuga-Barke, \& Oosterlaan, 2019; Pelham et al., 2014; Prasad et al., 2013). However, the effect of stimulants on areas of functioning in which 
skill development is required is much more limited, including academic achievement (Barbaresi, Katusic, Colligan, Weaver, \& Jacobsen, 2007; Massetti et al., 2008; Tamm et al., 2017), social functioning (Altszuler et al., 2017; Hoza et al., 2005; Pelham \& Bender, 1982; Whalen \& Henker, 1991) and parenting (Wells et al., 2006). These findings suggest that despite improving behavior and attention in the short-term, medication does not help children to develop the competencies needed (e.g., ability to learn academic concepts, social skills) to successfully navigate their schooling and interpersonal relationships, which are key predictors of long-term outcomes (Altszuler, Page, et al., 2015; Kuriyan et al., 2013; Molina et al., 2012).

The lack of stimulant effects in key domains and on long-term functioning provides clear rationale for the use of behavioral interventions (Altszuler, Macphee, et al., 2015; Macphee et al., 2017; Pelham, 2008). In contrast to medication, behavioral interventions target the development of skills by teaching the key adults in a child's life (e.g., parents, teachers) to reinforce appropriate behavior through the use of praise and rewards and to reduce inappropriate behavior through the use of punishments and privilege removal (Evans, Owens, \& Bunford, 2014; Kaminski, Valle, Filene, \& Boyle, 2008; Pelham \& Fabiano, 2008). Behavioral interventions produce positive effects on behavior and attention that are similar in magnitude to those produced by stimulants (Fabiano et al., 2007; Pelham et al., 2016; Pelham et al., 2014), and parents prefer treatment plans that include behavioral intervention (Schatz et al., 2015; Waschbusch et al., 2011). The use of behavioral intervention as a stand-alone treatment remains quite low compared to medication (likely a result of costs and complexity associated with implementing quality behavioral intervention), but the use of behavioral interventions in 
combination with stimulant medication has risen significantly in recent years (Danielson, Visser, et al., 2018), and is currently the most commonly recommended intervention by leading professional organizations (Pliszka, 2007; Wolraich et al., 2011).

Recent trends supporting the combination of behavioral intervention and medications appear promising for improving long-term outcomes of youth with ADHD. When medication and behavioral interventions are combined, low doses of both modalities can achieve the same effects as high doses of either unimodal treatment (Fabiano et al., 2007; Pelham et al., 2014). Using low intensity treatments is likely more palatable than using high intensity interventions to parents and teachers (e.g., Coles et al., under review). Using low doses of medication reduces side effects (Fabiano et al., 2007; Pelham, Manos, et al., 2005), and low intensity behavioral interventions are less costly and take less parent and teacher time to implement (Page et al., 2016). Therefore, combined interventions, relative to unimodal treatment, may improve long-term adherence. Further, there is some evidence that combined intervention allows for both symptom reduction and skill development (Altszuler et al., 2017; Tamm et al., 2017), which should lead to better long-term outcomes. However, the mechanisms by which combined interventions achieve their effects is not well understood, and the literature documenting long-term effects of behavioral and combined interventions is limited.

Recent evidence collected in our laboratory suggests that stimulant medication may paradoxically undermine the effects of behavioral interventions, which may help explain why despite the large, acute effects of stimulant medication and combined interventions, and despite most individuals with ADHD receiving these interventions at some point during childhood, the long-term prognosis for individuals with ADHD 
remains poor. Our laboratory recently completed a within-subjects crossover study in which children received intensive behavioral intervention combined with either stimulant medication or placebo for three weeks, and then received the opposite medication condition during the subsequent three weeks (Pelham at el., in preparation). Children who initiated treatment with combined intervention (i.e., stimulant medication plus intensive behavioral intervention) had twice as many negative verbalizations (i.e., talking back to adults, teasing peers) per day after medication was withdrawn compared to children who initiated treatment with placebo. The difference was observed despite the fact that children in the medication-first condition exhibited very low rates of negative verbalizations while taking medication. These results suggest that having medication onboard while participating in behavioral interventions reduces learning from behavioral contingencies. Post-hoc analyses of an earlier study conducted in our laboratory similarly suggest that the presence of medication interferes with response to intensive behavioral intervention (Chronis et al., 2004). Given the benefits associated with the use of combined interventions discussed above, understanding the mechanism by which stimulant medication may interfere with behavioral interventions is crucial for understanding how to improve long-term functioning among youth with ADHD.

The neurobiological literature suggests that stimulants may interfere with children's ability to learn from contingencies in their environment, such as those manipulated in behavioral interventions, through their action on the dopaminergic system (Frank, 2005). Stimulants increase tonic and phasic levels of the neurotransmitter dopamine (Schiffer et al., 2006; Volkow et al., 2001), functioning of which is depressed among individuals with ADHD (Ernst, Zametkin, Matochik, Jons, \& Cohen, 1998; 
Volkow et al., 2007; Volkow, Wang, \& Baler, 2011). Dopaminergic function is central to creating behavior-consequence associations (Schultz, 1998) in that phasic activations of dopamine in response to rewards result in learned behavior-reward associations over time (Cohen, Haesler, Vong, Lowell, \& Uchida, 2012; Fiorillo, Newsome, \& Schultz, 2008), whereas phasic dips following punishment (Cohen et al., 2012; Ungless, Magill, \& Bolam, 2004) result in learned avoidance of negative consequences (Frank, 2005). Stimulant medications increase levels of dopamine (Schiffer et al., 2006; Volkow et al., 2012; Volkow et al., 2001), which has been shown to enhance reward-based learning among adults with ADHD (e.g., Frank, Santamaria, O’Reilly, \& Willcutt, 2007). However, by increasing dopamine levels, stimulant use may also prevent punishmentinduced phasic dips in dopamine from reaching the level necessary to effectively shape behavior (Frank, 2005), an effect that has been consistently found among patients with Parkinson's Disease taking medication to increase dopamine levels (Bodi et al., 2009; Frank, O’Reilly, \& Seeberger, 2004).

Stimulant-induced insensitivity to punishment learning has not yet been evaluated among youth with ADHD, but if supported, would have significant clinical implications. Interventions that include punishment-based components (e.g., reprimands, point or privilege loss) more effectively reduce disruptive behavior and increase academic productivity than those relying on reward-based strategies alone (Abramowitz, O’Leary, \& Rosén, 1987; Acker \& O’Leary, 1987; Rosen, O’Leary, Joyce, Conway, \& Pfiffner, 1984), and have been found to result in better maintenance of on-task behavior (Sullivan \& O’Leary, 1990). Therefore, if children fail to learn behavior-consequence associations while taking stimulant medication, they may face serious difficulties once stimulant 
treatment is no longer active. The possibility that stimulant medication interferes with behavior-consequence associations is particularly worrisome given that the majority of individuals desist stimulant use during adolescence (McCarthy et al., 2009; Molina et al., 2009), a developmental period during which behavioral interventions are often less effective (Evans et al., 2014, 2017). Further, a recent study of treatment sequencing found that initiating treatment with stimulant medication reduces later uptake of behavioral intervention (Pelham et al., 2016). Therefore, failure to learn behavior-consequence associations during times of active stimulant use may result in youth with ADHD missing a critical window for developing the skills necessary for long-term success.

\section{Research Objectives and Hypotheses}

The current study aims to evaluate the impact of stimulant medication, specifically methylphenidate (MPH), on the ability of children with ADHD to learn from punishment and reward using a laboratory-based computer task. The first aim of the current study is to evaluate whether MPH impairs punishment-based learning on an associative learning task (Bodi et al., 2009). It is hypothesized that MPH will impair punishment-based learning as evidenced by lower accuracy on punishment-based learning trials compared to reward-based trials of the task when youth are taking MPH in contrast to similar performance across these trial types when taking a placebo. The second aim is to investigate whether the dose of MPH differentially impacts punishmentbased learning by comparing accuracy on punishment-based and reward-based trials across MPH doses. It is hypothesized that the effect of MPH will be dose-dependent such that higher doses of MPH will impair punishment-based learning to a greater extent than will lower doses of MPH. The final aim is to evaluate whether the intensity of 
punishment moderates the effect of MPH on punishment-based learning. It is hypothesized that the effect of MPH on punishment-based learning will be attenuated when punishment is intensified, as evidenced by increased accuracy on punishment-based trials of the associative learning task in an enhanced punishment condition relative to a regular punishment condition. 


\section{METHODOLOGY}

\section{Participants}

Participants were 27 children between the ages of 7 and $12(M=8.72$ years $)$

diagnosed with DSM-IV ADHD-Combined subtype (ADHD-C) who were referred to clinical services at the Center for Children and Families (CCF) at FIU. Children were referred to the CCF by local professionals or schools, media advertisements, billboards, or parent self-referral. Participation was limited to children who met criteria for ADHD-C because models of dopamine dysfunction best account for the profile of impairment experienced by these individuals, rather than by children who meet criteria for the predominately inattentive or hyperactive/impulsive subtypes (Johansen, Sagvolden, Aase, \& Russell, 2005). Sample characteristics are displayed in Table 1.

Evaluations of ADHD were made according to standard assessment procedures in the field (Pelham, Fabiano, \& Massetti, 2005). Specifically, symptoms of ADHD, oppositional defiant disorder (ODD) and conduct disorder (CD), were assessed using the NIMH Diagnostic Interview Schedule for Children IV, computerized version (Shaffer, 2000), and parent and teacher ratings on the Disruptive Behavior Disorders Scale (DBD; Pelham, Gnagy, Greenslade, \& Milich, 1992). Cross-situational impairment was assessed using parent and teacher ratings on the Impairment Rating Scale (IRS; Fabiano et al., 2006). Two doctoral level clinicians independently reviewed intake assessments to make diagnoses for each child who participated in the study. Twenty-four participants received a concurrent diagnosis of ODD and no participants were diagnosed with CD.

Children were excluded from the study on the basis of the following criteria: (1) a Full Scale IQ below 80 according to the Wechsler Abbreviated Scale of Intelligence, 
Second Edition (WASI-II; Wechsler, 2011); (2) receiving psychotropic medication for conditions other than ADHD or active medical or psychiatric conditions that could be worsened by stimulants at the time of study enrollment; (3) documented intolerance to MPH medications; (4) concurrent diagnosis of DSM-5 Autism Spectrum Disorder (ASD) as stimulants have been found to have reduced efficacy and tolerability in this population (Research Units on Pediatric Psychopharmacology (RUPP) Autism Network, 2005); and (5) comorbid conditions requiring psychotropic medication or emergent treatment (e.g., mania, active suicidal ideation).

One participant withdrew from the study because of scheduling conflicts resulting from the parent's work schedule, partial data were collected and analyzed. All other participants completed the study.

\section{Procedures}

The study was approved by the Western Institutional Review Board (Protocol \#: 20161191). Participants provided informed consent/assent prior to the implementation of study procedures. All children underwent an initial assessment to determine appropriateness for the study, which included an evaluation of ADHD, ODD and CD, a brief cognitive assessment, and a physical exam clearing participants to be prescribed stimulant medications.

Setting. The study was conducted within a Saturday Treatment Program (SatTP), an 8-week behavioral peer intervention for children with ADHD modeled after the Summer Treatment Program (Pelham et al., 2010). The SatTP was held for 3 hours on Saturday mornings and afternoons, and sessions were held approximately one week apart. Children were placed in 3 groups of 10 to 15 , supervised by 5 to 7 paraprofessional counselors. 
Counselors were supervised by an advanced doctoral student and a licensed clinical psychologist. Children participated in recreational activities (e.g., soccer drills and games) and cooperative learning activities. Staff members implemented a comprehensive behavior management system throughout the SatTP.

Design. The study used a 4 (medication: placebo; MPH: 0.15, 0.3, $0.6 \mathrm{mg} / \mathrm{kg} / \mathrm{dose}$ ) x 2 (trial type: reward, punishment) x 2 (task condition: regular punishment, enhanced punishment) within-subjects design to evaluate MPH and punishment manipulations on children's ability to learn associations from rewards and punishments. Study conditions were randomly assigned across the 8 days of the SatTP, such that each child received one condition per program day. Table 2 displays a sample study schedule for one participant.

Medication. Doses of MPH that most closely approximate $0.15,0.3$, and 0.6 $\mathrm{mg} / \mathrm{kg} / \mathrm{dose}$ and placebo were randomized by day over a total of the 8 days of the SatTP. The doses used in the current study represent standard dosing for low, moderate, and high doses of MPH respectively (Fabiano et al., 2007; Pelham et al., 2014; Pelham, Manos, et al., 2005). Order of medication condition was counter-balanced across participants. A portion of participants $(n=11)$, were participating in a concurrent medication study in which they were prescribed long-acting MPH on weekends, when study testing sessions were conducted. Ten of these children were prescribed OROS-MPH (Concerta) and one was prescribed Metadate $\mathrm{CD}$. All other participants were prescribed immediate-release MPH. Long-acting and short-acting forms of MPH have been shown to have equivalent effects on children's attention, behavior, and productivity (Döpfner et al., 2004; Pelham et al., 2001; Swanson et al., 2004). Testing sessions were conducted within the timecourse for the appropriate formulation of MPH. 
Parents were provided dated blister packs containing medication capsules, sequenced according to the randomization schedule. Medication administration was confirmed by SatTP staff with parents at the start of each program day. Parents were also asked to return used blister packs as a check on medication adherence. Medication was delivered in a gelatin capsule so that participants, their parents, and staff members were not aware of medication condition. Adverse effects were monitored daily through parent and staff ratings on the Pittsburgh Side Effect Rating Scale (Pelham, 1993), a measure that has been routinely used in medication studies conducted within the STP (e.g., Pelham et al., 1999, 2001, 2005, 2014). No adverse events were reported during the study.

Task Procedures. One testing session was conducted per SatTP day. Task conditions were randomized by day and order was counter-balanced across participants. On four days, participants received the enhanced punishment condition and on four days participants received the regular punishment condition (Table 2). The computer task was administered individually to each child by a research assistant on a Dell laptop. The sessions were conducted in a quiet room and lasted approximately 15 minutes. Participants sat at a comfortable viewing distance from the laptop. Participants wore headphones and computer volume was kept at a standard level for all testing sessions.

Associative Learning Task. A modified version of a probabilistic learning task previously used by Bodi et al. (2009) to measure the impact of dopamine on associative learning among adults with Parkinson's Disease was used in the current study. The task measures participants' ability to learn stimuli-category associations through trial and error (see Table 3 for a description of the task structure). Stimuli were four kaleidoscopic 
images, selected at random from a library of over 250 images (see Figure 1 for sample images). Unique images were presented during each testing session. Two of the four images presented during each testing session belonged to category " $\mathrm{A}$ " and the remaining two images belonged to category "B." One image from each category was associated with rewards (reward trials), such that participants earned points when they matched the image to the appropriate category. The remaining two images (one belonging to category "A" and one belonging to category "B") were associated with punishment (punishment trials), such that participants lost points when images were matched to the incorrect category. Punishment and reward trials were interspersed throughout each testing session. Two different punishment trial types were tested during unique testing sessions: regular and enhanced punishment (described in more detail below). Probabilistic feedback was provided across trial types, meaning that participants received accurate feedback on $80 \%$ of trials and inaccurate feedback on $20 \%$ of trials. Probabilistic feedback was introduced because pilot testing among youth ages 7-11 diagnosed with ADHD-C resulted in mean task performance above $80 \%$ across reward and punishment trial types, indicating potential ceiling effects (Altszuler, Macphee et al., 2016). Probabilistic feedback has been used in previous studies (Bodi et al., 2009; Frank et al., 2007; Mattfeld, Gluck, \& Stark, 2011) to introduce variability in task performance and to prevent ceiling effects.

Each testing session consisted of 160 learning trials (40 trials/image) split into four consecutive testing blocks. The order of stimuli was counterbalanced across participants. Each testing session began with the presentation of one of the four images with the question "Is this an 'A' or a 'B'?"' below the image, followed by the two possible categories. Stimuli were presented until the participant responded and trials were 
separated by the presentation of a blank page for $1000 \mathrm{msec}$. Participants' point totals were displayed in the bottom right corner of the screen and were updated continuously depending on performance. On reward trials (Figure 1, Panel A), participants earned 20 points when the correct category was selected. To mimic feedback a child might receive from a parent or teacher (e.g., verbal praise, positive facial expression), point gain was associated with visual and audio feedback. Participants were presented with " +20 " in green text, a happy face icon, and the "cha-ching" sound of a cash register. When the incorrect category was selected, participants did not receive any feedback or lose points. Across both punishment conditions (i.e., regular and enhanced), participants did not receive any feedback when the correct category was selected on punishment trials (Figure 1, Panels B and C). In the regular punishment condition, participants lost 20 points when the incorrect category was selected. Point loss was accompanied with visual and audio feedback, including "-20" presented in red text, a red sad face image, and a buzzer sound (Figure 1, Panel B). These punishments were intensified in the enhanced punishment condition such that participants lost 100 points, accompanied by “-100" presented in red text, a red angry face icon, and an airhorn sound (Figure 1, Panel C).

Prior to testing, task administrators provided participants with standardized instructions for completing the task. Participants were told they would be learning to match pictures to the correct letter. Category and trial types were explained to participants. Participants were also told that they would receive inaccurate feedback at times. Participants were instructed to keep as many points as possible and were shown all potential prizes for which points could be exchanged upon completion of the task. Participants were provided with one practice block prior to the first testing session to 
ensure understanding of task procedures. During task administration, research assistants provided redirection if children engaged in off-task behavior and provided positive feedback for effort, but did not provide performance feedback. At the end of the task, children exchanged points for prizes, which ranged in point value depending on desirability.

\section{Dependent Measure}

Performance on the probabilistic learning task was analyzed as the dependent measure. Total correct categorizations out of total possible trials was calculated for each trial type (i.e., reward, punishment).

\section{Analyses and Handling of Missing Data}

Multilevel modeling (Hayes, 2006) was used to analyze the effect of study manipulations on task performance, with 128 observations per child (i.e., reward and punishment trial performance across 4 blocks per testing session, across 8 testing sessions). The model was fit for task performance on both trial types. Initial models indicated that the order of testing condition (e.g., condition received on day 5 versus day 8) and other potential covariates, including participant IQ, age, race, and ethnicity, failed to explain variance in task performance and were therefore dropped from the final model. Initial analyses also indicated that the interaction of block and study manipulations (i.e., punishment condition, medication dose) did not explain variance in task performance and those interactions were also dropped from model specification.

In the final model, trial performance was regressed on a random factor for child and several fixed effects: (a) medication dose (i.e., placebo, $0.15 \mathrm{mg} / \mathrm{kg}, 0.3 \mathrm{mg} / \mathrm{kg}, 0.6$ $\mathrm{mg} / \mathrm{kg}$ ), (b) trial type (i.e., reward or punishment), (c) punishment condition (i.e., regular 
or enhanced), (d) block, (e) the interaction of trial type and punishment condition, (f) the interaction of medication dose and trial type, $(\mathrm{g})$ the interaction of medication dose and punishment condition, (h) the three-way interaction of medication, trial type, and punishment condition, and (i) the interaction of block and trial type. The effects testing study aims are (f) and (h). Effect (f) evaluates Aims 1 and 2: Does medication differentially impact learning from punishment compared to reward? Effect (h) evaluates Aim 3: Does dose of punishment moderate the effect of MPH on punishment learning? Multilevel models were conducted in SPSS 20.0. Where models indicated statistically significant effects, simple slope regressions (Preacher, Curran, \& Bauer, 2006) were conducted using the reghelper package in $R$.

Overall, $13.4 \%$ of task performance data were missing as a result of participant absences $(10.6 \%)$ or non-adherence to medication condition $(2.8 \%)$. The multilevel modeling framework handles unbalanced observations on the outcome variable for data missing at random. 


\section{RESULTS}

Table 4 displays raw means and standard deviations of task performance by trial type, punishment condition, and medication dose. Table 5 displays results of the multilevel model.

\section{Learning Over Time}

The effect of study manipulations on task performance was evaluated over the course of four blocks per testing session to assess learning over time. There was no significant direct effect of task block; however, there was a significant block by trial type interaction $(p<0.05)$. As displayed in Figure 2, children's learning improved over time on punishment trials (Block 1 marginal mean=0.52, Block 4 marginal mean=0.59), whereas

children's initial performance on reward trials was more accurate relative to punishment trials (Block 1 marginal mean=0.62) and remained consistent throughout testing (Block 4 marginal mean=0.64), $t(1438)=4.51, p<0.001$.

\section{Direct Effects of Study Manipulations}

There was no significant direct effect of medication, nor any significant medication by trial type (i.e., reward, punishment) interactions. That is, medication did not improve children's associative learning on punishment- or reward-based learning trials.

There was a significant direct effect of trial type $(p<0.001)$ such that children associated more stimuli with the correct categories on reward trials (marginal mean=0.62) compared to punishment trials (marginal mean=0.57). However, as mentioned above, there was a significant block by trial type interaction, such that this effect was no longer significant by block $4, t(328)=-0.48, p=0.64$. 
There was a significant direct effect of punishment condition $(p<0.01)$, such that children's task performance improved across trial types (i.e., reward and punishment) when they received the regular punishment condition (marginal mean=0.61) compared to the enhanced condition (marginal mean $=0.58$ ).

\section{Interaction of Medication, Trial Type, and Punishment}

The three-way interaction of medication, trial type, and punishment condition was significant for the moderate dose of MPH $(p<0.01)$ and was trending towards significance for the high dose $(p<0.10)$. Simple slopes regressions indicated that higher doses of medication $(0.3$ and $0.6 \mathrm{mg} / \mathrm{kg} \mathrm{MPH})$ had a differential effect on reward trial performance when participants received the enhanced punishment condition (Figure 3, Panel A). Specifically, in the enhanced punishment condition, participants performed significantly

worse on reward trials when prescribed placebo (marginal mean $=0.55), t(1438)=3.26, p$ $<0.01$, and $0.15 \mathrm{mg} / \mathrm{kg} \mathrm{MPH} \mathrm{(marginal} \mathrm{mean=0.58),} t(1438)=3.11, p<0.01$, compared to their performance when they received the regular punishment condition (placebo marginal mean $=0.64,0.15 \mathrm{mg} / \mathrm{kg}$ marginal mean=0.66). The same effect was not observed for punishment trials (Figure 3, Panel B). 


\section{DISCUSSION}

The current study evaluated the impact of MPH on associative learning among youth with ADHD. The study measured the effect of four doses of MPH (i.e., placebo, low, moderate, and high) and two punishment conditions (i.e., regular and enhanced) on children's performance across reward- and punishment-based trial types on an associative learning task. Overall, results did not support hypotheses that stimulant medication interferes with children's punishment-based learning, and results indicated that this effect was not seen at any dose of medication. The study similarly did find support for intensifying punishment as a method for enhancing punishment-based learning. Across conditions, children performed only slightly above chance levels (averaging 62\% accuracy on reward trials and $57 \%$ accuracy on punishment trials), indicating that the probabilistic nature of the task may have been too difficult to detect planned effects. Results did indicate that children demonstrated better overall performance when they were rewarded for correct responses relative to when they were punished for incorrect responses, regardless of medication status. Further, results indicated worse performance under more intensive punishment conditions, a finding that was attenuated by higher doses of medication. These findings, and their implications, are discussed in turn below.

\section{Lack of Main Effects of Medication}

The lack of a significant main effect of MPH in the current study is surprising, given that stimulant medication has been shown to improve performance of youth with ADHD on a variety of laboratory tasks (e.g., Bubnik, Hawk, Pelham, Waxmonsky, \& Rosch, 2015; Groen, Mulder, Wijers, Minderaa, \& Althaus, 2009; Rosch et al., 2015; Strand et al., 2012). According to Frank's (2005) dynamic dopamine model, stimulant 
medication would be expected to improve performance on reward-based trials as a result of increased dopamine levels, as has been observed with adults with Parkinson's Disease (Bodi et al., 2009; Frank, O’Reilly, \& Seeberger, 2004) and adults with ADHD (Frank et al., 2007). Failure to find a stimulant effect on reward-based learning in the current study may have been caused by limited variability in reward-based trial performance over time. Across punishment conditions, block 4 learning on reward trials averaged approximately $58 \%$ accuracy when participants were unmedicated and ranged from 60-65\% accuracy when participants were taking medication. In comparison, unmedicated adults with ADHD performed similarly low (approximately 60\% accuracy) when learning from reward-based stimuli, but medication improved performance to approximately $75 \%$ accuracy on a similar task (Frank et al., 2007). The current study is the first to use such a probabilistic learning paradigm in children, and the lack of learning over time in response to rewards suggests that the task may have been too difficult for children to achieve over $65 \%$ accuracy on reward-based trials.

Following the dynamic dopamine model (Frank, 2005), stimulant medication would also be expected to impair punishment-based learning by blocking phasic dips in dopamine levels, an effect that was not observed in the current study. Frank and colleagues (2007) also failed to show that medication impaired punishment-based learning among individuals with ADHD, to which authors attributed to a floor effect as participants only demonstrated optimal responding to punishment-based stimuli about $60 \%$ of the time. A floor effect may also explain lack of findings in the current study as punishment-based learning averaged approximately 57\% accuracy across conditions. However, learning from punishment did improve significantly over time, and whereas 
medication status did not moderate learning rate in the current study, it is possible that additional learning opportunities may have produced sufficient variability in performance to detect a medication effect.

While task calibration appears to be a probable explanation for the failure of the current study to support Frank's dynamic dopamine model, it is also likely that factors other than stimulant-induced dopamine levels influenced reward- and punishment-based performance on the associative learning task. Other potential contributing factors are discussed below.

\section{Differences in Punishment- and Reward-Based Learning}

In the current study, children demonstrated higher overall performance when they were rewarded for correct responses compared to when they were punished for incorrect responses on the associative learning task. These results differ from findings in the behavioral intervention literature, which show that punishment-based strategies, including the loss of points and privileges, are more effective at shaping behavior than are reward-based strategies (Abramowitz et al., 1987; Acker \& O’Leary, 1987; Pfiffner \& O’Leary, 1987; Rosen et al., 1984). However, the relatively large initial difference in performance across punishment and reward trials observed in the current study (approximately 11 percentage points), decreased by more than half by the last block of the task and the difference between the two trial types was no longer statistically significant by block 4 . That is, despite understanding reward-stimuli associations better at the outset, children demonstrated more learning over time in response to punishment stimuli, tempering conclusions that children with ADHD learn better from rewards. Given that the rate of punishment-based learning increased over time while reward-based 
learning remained consistent, it is possible that accuracy on punishment-based stimuli would have continued to improve and perhaps match or surpass accuracy on rewardbased stimuli with additional learning trials. However, as mentioned above, it is also possible that performance on reward trials was stilted by task difficulty. Adding additional learning opportunities and increasing the percentage of accurate feedback on future iterations of the task may help provide clarity regarding the effectiveness of punishment- and reward-based learning strategies for children with ADHD.

The differential rate of learning from punishment and reward observed in the current study is interesting, as the effect has not been found in studies using the same task with other populations (Bodi et al., 2009; Mattfeld et al., 2011), or in the behavioral intervention literature (Acker \& O’Leary, 1987; Iwata \& Bailey, 1974; Pfiffner \& O'Leary, 1987; Rosen et al., 1984). The task experience, particularly the experience of receiving no feedback, may have contributed to the differential learning rate across trial types. When children correctly matched images to the appropriate category on reward trials, they received immediate feedback that they were correct. That is, they only had to make a "one-step" association that Image 1 equaled "A." In contrast, on punishment trials, children received feedback when they were incorrect, meaning they had to process that 1) Image 2 did not equal "B," and that 2) Image 2 therefore equaled "A." Relative to the one-step process of learning reward-stimuli associations, the two-step process of learning punishment-stimuli associations may have therefore placed greater working memory demands on children, an area that is quite impaired for children with ADHD (Kasper, Alderson, \& Hudec, 2012). The no feedback condition likely added even greater working memory demands, as no feedback could either mean that children incorrectly 
associated an image to a category on a reward trial or correctly associated an image to a category on a punishment trial, meaning that children had to remember 1) whether the image was associated with reward or punishment and 2) to which category the image belonged. Separating punishment and reward trials into different testing sessions may help reduce the cognitive load experienced by children when completing the task, allowing for greater clarification beyond the current study regarding the trial type from which children with ADHD learn best.

The probabilistic learning task used in the current study attempted to tease apart effects from rewards and punishments by associating feedback types to different images within a testing session. However, reward and cost components were still mixed in the current study such that point losses and gains contributed to the same total point bank, which participants exchanged for desirable prizes at the end of the session. The overall task experience therefore mirrored a token economy, in which children earn points for positive behavior and lose points for inappropriate behaviors, and points are then exchanged for privileges and rewards (Altszuler, Macphee, et al., 2015). While such procedures represent contingencies implemented as a part of good clinical practice for youth with ADHD (Evans et al., 2017), combining reward and punishment trials within a single testing session may have also contributed to difficulties teasing apart learning effects from reward versus cost strategies, as has been found in the behavioral intervention literature (Iwata \& Bailey, 1974; Kaufman \& O’Leary, 1972; McGoey \& DuPaul, 2000). Further separating rewards and consequences into separate testing sessions may help address these limitations. 
While it is unclear which strategy led to better learning in the current study, children did respond (albeit in different ways) to both reward- and punishment-based strategies. Findings related to reward- and punishment-based learning suggest that, consistent with common clinical recommendations, both reward- and punishment-based strategies should be used in the treatment of children with ADHD. Punishment and reward strategies are both widely recognized components of effective behavioral interventions for youth with ADHD and disruptive behavior problems (DuPaul, Eckert, \& Vilardo, 2012; Kaminski et al., 2008), and all widely used behavioral parenting programs teach caregivers to use both positive reinforcement and punishment strategies, such as time out and privilege removal (e.g., Barkley, 2013; Cunningham et al., 1993; McMahon \& Forehand, 2005).

\section{Differences by Punishment Condition}

It was hypothesized that intensifying punishment would lead to better learning, as doing so would lead to a larger phasic dip in dopamine (Schultz, 1998), counteracting the effect of stimulant-induced increases in dopamine. The current study is the first to evaluate the interaction of differing intensities of punishment and stimulant medication, and support was not found for this hypothesis. In contrast, participants performed worse overall when they received the enhanced punishment condition, which consisted of a loss of 100 points accompanied by an angry face and unpleasant sound, compared to when they received the regular punishment condition, which consisted of a loss of 20 points accompanied by a less aversive face and sound.

Interestingly, the deterioration of learning in the enhanced punishment condition was driven nearly entirely by performance on reward trials, on which participants 
performed approximately 4 percentage points worse in the enhanced condition. In contrast, there was little difference in punishment trial performance across the enhanced and regular punishment conditions. Learning deterioration in the enhanced punishment condition suggests that in the context of a more frustrating experience, children had more difficulty learning from reward-based stimuli. Children may have shown reduced performance on reward trials because performance on such trials was less meaningful in the enhanced punishment condition, as children only earned 20 points relative to losing 100 points. The fact that punishment condition influenced reward performance indicates that the overall task experience influenced children's ability to learn from rewards and punishments, providing additional support for separating punishment and reward testing sessions, as discussed above.

Children were able to maintain their performance on punishment trials (relative to reward trials) when they received the enhanced punishment condition, indicating that they were likely somewhat more motivated to avoid a large point loss. However, the presence of the enhanced punishment condition negatively impacted children's overall performance. It is likely (and was observed anecdotally), that children became more frustrated when they received the enhanced punishment condition. Overly strong punishments and criticisms, particularly relative to the strength of rewards, lead to increases in disruptive behavior and poorer behavioral outcomes (Musser, Karalunas, Dieckmann, Peris, \& Nigg, 2017; Patterson, 2002). Children with ADHD are also more likely to give up in the face of frustration (Milich, 1994; Milich \& Okazaki, 1991), which may have contributed to poorer performance on reward trials in the enhanced punishment condition relative to the regular punishment condition. 


\section{Medication, Punishment Condition, and Trial Type Interaction}

As mentioned above, participants performed worse on reward trials when they received the enhanced punishment condition. However, deterioration of reward-based learning was attenuated by medication such that at moderate and high doses $(0.3-0.6$ $\mathrm{mg} / \mathrm{kg} \mathrm{MPH}$ ), participants performed similarly across enhanced punishment (marginal means ranged from $63-66 \%$ accuracy) and regular punishment (marginal means ranged from $62-65 \%$ accuracy) conditions. In contrast, when participants were taking a placebo or a low dose $(0.15 \mathrm{mg} / \mathrm{kg} \mathrm{MPH})$, they fared worse when they received the enhanced punishment (marginal means ranged from $55-58 \%$ accuracy) relative to when they received the regular punishment (marginal means ranged from $64-66 \%$ accuracy). These findings indicate that higher doses of medication helped offset the negative effects of the enhanced punishment condition on reward trial performance.

These findings are consistent with previous work examining the impact of stimulant medication on persistence among youth with ADHD. Previous work by Milich and colleagues (1991) demonstrated that children with ADHD performed the same on a solvable task when taking a moderate dose of medication $(0.3 \mathrm{mg} / \mathrm{kg} \mathrm{MPH})$ relative to placebo. However, when given a frustrating task (a nonsense word search), children were much better able to persist when taking medication, and performed better on subsequent solvable puzzles, relative to their performance when taking placebo. Similarly, Pelham and colleagues (1997) found that a moderate dose $(0.3 \mathrm{mg} / \mathrm{kg} \mathrm{MPH})$ improved persistence and reaction to failure among children with ADHD, and that research assistants (unaware of child medication status) rated children taking medication as putting forth more effort. Findings from the current study add to the literature that 
medication provides a buffering effect when youth with ADHD are faced with frustrating situations.

\section{Limitations}

The current study was the first to evaluate stimulant-induced insensitivity to punishment-based learning among youth with ADHD and study limitations may help explain why support was not found for Frank's (2005) dynamic dopamine model among youth with ADHD. The current study was also the first to use the probabilistic learning task with children, and findings suggest that the task calibration used in the current study was likely too challenging for participants' developmental level. While learning did appear to occur from both trial types (as evidenced by better initial performance on reward trials and significantly improved learning over time on punishment trials), the highest accuracy achieved across conditions was $65 \%$. Providing a higher percentage of accurate feedback will lead to better task performance (Altszuler, Macphee, et al., 2016), and might allow for detection of medication effects. It also appears that additional learning opportunities would have been helpful, particularly for punishment-based trials, as learning appeared to follow a linear trajectory and performance may have continued to improve with additional trials. As discussed previously, it is also possible that the differing cognitive loads posed by reward and punishment trials served as a confound, and that mixing punishment and reward trials in the same testing session influenced task performance. Limitations associated with the task development should be taken into account when designing future studies to evaluate the impact of stimulant medication on associative learning among youth with ADHD. 
In addition to limitations associated with the task, the study sample was small and may have been underpowered to detect smaller effects. However, previous research indicates that medication should have relatively large effects on task performance (Bubnik et al., 2015; Rosch et al., 2015; Strand et al., 2012). Further, the use of a withinsubjects design increases power and did allow for the detection of several significant effects in the current study. As with most studies conducted with youth with ADHD, the study sample was predominately male, and as with most studies conducted in South Florida, participants were predominately Hispanic/Latino. Study results may therefore lack generalizability.

\section{Clinical Implications}

The present study has several implications relevant to the treatment of children with ADHD. First, children learned from both reward- and punishment-based strategies, supporting current clinical recommendations to use both forms of behavior modification with youth with ADHD. Findings also highlight the importance of ensuring that reward and punishment-based strategies are balanced. When children lost more points than they earned, their performance was affected, likely due to frustration. Findings are in line with clinical recommendations to provide positive feedback at a higher frequency than negative redirections (Altszuler, Macphee, et al., 2015), because, as was seen in the current study, overly negative feedback results in worse behavior. Further, tasks that are too challenging may result in children giving up altogether (Milich et al., 1991; Milich \& Okazaki, 1991). Consistent with past research, findings from the current study also indicate that stimulant medication improves performance among youth with ADHD when faced with frustrating or challenging tasks. These findings indicate that it can be helpful 
to have medication onboard when children must face challenging or frustrating tasks. However, psychosocial interventions aimed at improving frustration management and teaching parents and teachers to set achievable goals for youth with ADHD have also been found to be effective (Kolko, Lindhiem, Hart, \& Bukstein, 2014; Waxmonsky et al., 2016), and as discussed previously, interventions that teach skills are likely to lead to better long-term functioning.

\section{Conclusions and Future Directions}

Findings from the current study failed to support hypotheses that stimulant medication would impair punishment-based learning, and that enhanced punishment would attenuate these effects. One explanation for failure to find support for hypotheses is that the associative learning task used in the current study was not ideally calibrated to youth with ADHD. Due to this limitation, the hypothesis that medication interferes with punishment-based learning cannot be ruled out. Future work should continue to examine this hypothesis among youth with ADHD using suggested modifications to the current task to allow for more variability in task performance and to better isolate effects from reward- and punishment-based learning. Should support be found for this mechanism in a lab-based setting, it will be crucial to conduct studies in clinical settings to better understand how findings translate to clinical practice recommendations for youth with ADHD. Many factors influence contingency-based learning among youth with ADHD, and findings from the current study suggest that emotion regulation and working memory likely play a role. Future work should continue to explore how these variables impact children's response to behavioral interventions and stimulant medication. Lastly, many factors likely contribute to the gap between short-term efficacy and positive long-term 
outcomes for youth with ADHD, including poor long-term adherence to treatment, reduced motivation to implement behavioral interventions following stimulant treatment, and lack of resources for/availability of chronic models of care for individuals with ADHD. More work targeting the development of long-term services for individuals with ADHD and engagement in such services is sorely needed to improve the long-term prognosis of these individuals. 


\section{REFERENCES}

Abramowitz, A. J., O’Leary, S. G., \& Rosén, L. A. (1987). Reducing off-task behavior in the classroom: A comparison of encouragement and reprimands. Journal of Abnormal Child Psychology, 15(2), 153-163. https://doi.org/10.1007/BF00916345

Acker, M. M., \& O’Leary, S. G. (1987). Effects of reprimands and praise on appropriate behavior in the classroom. Journal of Abnormal Child Psychology, 15(4), 549-557. https://doi.org/10.1007/BF00917240

Altszuler, A. R., Macphee, F. L., Merrill, B. M., Mattfeld, A., Raiker, J. S., Lesperance, S., Gnagy, E. M., Greiner, A. R., Coles, E., \& Pelham, W. E. (2016, October). The effect of methylphenidate on associative learning among youth with ADHD: Results from a pilot study. Poster presented at the annual convention of the Association for Behavioral and Cognitive Therapies, New York, NY.

Altszuler, A. R., Macphee, F. L., Merrill, B. M., Morrow, A. S., Schatz, N. K., \& Pelham, W. E. (2015). Attention-deficit hyperactivity disorder. In J. Piacentini \& C. Flessner (Eds.), Clinical handbook of psychological disorders in children and adolescents: A stepby-step treatment manual.

Altszuler, A. R., Morrow, A. S., Merrill, B. M., Bressler, S., Macphee, F. L., Gnagy, E. M., ... Pelham, Jr., W. E. (2017). The Effects of Stimulant Medication and Training on Sports Competence Among Children With ADHD. Journal of Clinical Child \& Adolescent Psychology, 00(00), 1-13. https://doi.org/10.1080/15374416.2016.1270829

Altszuler, A. R., Page, T. F., Gnagy, E. M., Coxe, S., Arrieta, A., Molina, B. S. G., \& Pelham, W. E. (2015). Financial dependence of young adults with childhood ADHD. Journal of Abnormal Child Psychology, 43(8). https://doi.org/10.1007/s10802-015-00939

Barbaresi, W. J., Katusic, S. K., Colligan, R. C., Weaver, A. L., \& Jacobsen, S. J. (2007). Modifiers of Long-Term School Outcomes for Children with Attention-Deficit / Hyperactivity Disorder : Does Treatment with Stimulant Medication Make a Difference ? Results from a Population-Based Study. Journal of Developmental and Behavioral Pediatrics, 28, 274-287. https://doi.org/10.1097/DBP.0b013e3180cabc28

Barkley, R. A. (2015). Attention-Deficit Hyperactivity Disorder: A Handbook for Diagnosis \& Treatment (4th ed.; R. A. Barkley, ed.). New York: Guilford Press.

Barkley, Russell A, Murphy, K. R., \& Fischer, M. (2008). ADHD in Adults: What the Science Says. New York: Guilford Press.

Bodi, N., Keri, S., Nagy, H., Moustafa, A., Myers, C. E., Daw, N., ... Gluck, M. A. (2009). Reward-learning and the novelty-seeking personality: A between-and within- 
subjects study of the effects of dopamine agonists on young parkinsons patients. Brain, 132, 2385-2395. https://doi.org/10.1093/brain/awp094

Bubnik, M. G., Jr, L. W. H., Jr, W. E. P., Waxmonsky, J. G., \& Rosch, K. S. (2015). Reinforcement Enhances Vigilance Among Children With ADHD : Comparisons to Typically Developing Children and to the Effects of Methylphenidate. 149-161. https://doi.org/10.1007/s10802-014-9891-8

Chronis, A. M., Fabiano, G. A., Gnagy, E. M., Onyango, A. N., Pelham, W. E., LopezWilliams, A., ... Seymour, K. E. (2004). An evaluation of the summer treatment program for children with attention-deficit/hyperactivity disorder using a treatment withdrawal design. Behavior Therapy, 35, 561-585. https://doi.org/10.1016/S0005-7894(04)80032-7

Chronis, A. M., Pelham, W. E., Gnagy, E. M., Roberts, J. E., \& Aronoff, H. R. (2003). The impact of late-afternoon stimulant dosing for children with ADHD on parent and parent-child domains. Journal of Clinical Child and Adolescent Psychology: The Official Journal for the Society of Clinical Child and Adolescent Psychology, American Psychological Association, Division 53, 32(1), 118-126. https://doi.org/10.1207/S15374424JCCP3201_11

Coles, E. K., Pelham III, W. E., Fabiano, G. A., Gnagy, E. M., Burrows-Maclean, L., Wymbs, B. T., Chacko, A., Walker, K. S., Wymbs, F., Robb, J., Garefino, A., Hoffman, M. T., Massetti, G. M., Page, T. F., Waschbusch, D. A., Waxmonsky, J. G., \& Pelham Jr., W. E. (under review at Journal of Clinical Child and Adolescent Psychology). Randomized trial of first-line behavioral intervention to reduce need for medication in children with ADHD.

Cohen, J. Y., Haesler, S., Vong, L., Lowell, B. B., \& Uchida, N. (2012). Neuron-typespecific signals for reward and punishment in the ventral tegmental area. Nature, 482(7383), 85-88. https://doi.org/10.1038/nature10754

Danielson, M. L., Bitsko, R. H., Ghandour, R. M., Holbrook, J. R., Kogan, M. D., \& Blumberg, S. J. (2018). Prevalence of Parent-Reported ADHD Diagnosis and Associated Treatment Among U.S. Children and Adolescents, 2016. Journal of Clinical Child and Adolescent Psychology, 47(2), 199-212. https://doi.org/10.1080/15374416.2017.1417860

Danielson, M. L., Visser, S. N., Chronis-Tuscano, A., \& DuPaul, G. J. (2018). A National Description of Treatment among United States Children and Adolescents with AttentionDeficit/Hyperactivity Disorder. Journal of Pediatrics, 192, 240-246.e1. https://doi.org/10.1016/j.jpeds.2017.08.040

Döpfner, M., Gerber, W. D., Banaschewski, T., Breuer, D., Freisleder, F. J., Gerber-Von Müller, G., ... Lehmkuhl, G. (2004). Comparative efficacy of once-a-day extendedrelease methylphenidate, two-times-daily immediate-release methylphenidate, and 
placebo in a laboratory school setting. European Child and Adolescent Psychiatry, Supplement, 13(1). https://doi.org/10.1007/s00787-004-1009-3

Doshi, J. A., Hodgkins, P., Kahle, J., Sikirica, V., Cangelosi, M. J., Setyawan, J., ... Neumann, P. J. (2012). Economic impact of childhood and adult attentiondeficit/hyperactivity disorder in the United States. Journal of the American Academy of Child and Adolescent Psychiatry, 51(10), 990-1002.e2. https://doi.org/10.1016/j.jaac.2012.07.008

Dougherty, D. D., Bonab, A. A., Spencer, T. J., Rauch, S. L., Madras, B. K., \& Fischman, A. J. (1999). Dopamine transporter density in patients with attention deficit hyperactivity disorder. The Lancet, 354(9196), 2132-2133. https://doi.org/10.1016/S0140-6736(99)04030-1

DuPaul, G. J., Eckert, T. L., \& Vilardo, B. (2012). The effects of school-based interventions for attention deficit hyperactivity disorder: A meta-analysis 1996-2010. School Psychology Review, 41(4), 387-412. Retrieved from http://search.proquest.com/docview/1319240445?pq-origsite=gscholar

Ernst, M., Zametkin, A. J., Matochik, J. A., Jons, P. H., \& Cohen, R. M. (1998). DOPA decarboxylase activity in attention deficit hyperactivity disorder adults. A [fluorine18]fluorodopa positron emission tomographic study. The Journal of Neuroscience: The Official Journal of the Society for Neuroscience, 18(15), 5901-5907.

Evans, S. W., Owens, J. S., \& Bunford, N. (2014). Evidence-based psychosocial treatments for children and adolescents with attention-deficit/hyperactivity disorder. Journal of Clinical Child \& Adolescent Psychology, 43, 527-551. https://doi.org/10.1080/15374410701820117

Evans, S. W., Owens, J. S., Wymbs, B. T., \& Ray, A. R. (2017). Evidence-Based Psychosocial Treatments for Children and Adolescents With Attention Deficit/Hyperactivity Disorder. Journal of Clinical Child \& Adolescent Psychology, 4416(December), 1-42. https://doi.org/10.1080/15374416.2017.1390757

Fabiano, G. A., Pelham, W. E., Coles, E. K., Gnagy, E. M., Chronis-Tuscano, A., \& O'Connor, B. C. (2009). A meta-analysis of behavioral treatments for attentiondeficit/hyperactivity disorder. Clinical Psychology Review, 29, 129-140. https://doi.org/10.1016/j.cpr.2008.11.001

Fabiano, G. A., Pelham, W. E., Gnagy, E. M., Burrows-maclean, L., Coles, E. K., Chacko, A., ... Robb, J. A. (2007). The single and combined effects of multiple intensities of behavior modification and methylphenidate for children with attention deficit hyperactivity disorder in a classroom setting. School Psychology Review, 36(2), 195-216. 
Fabiano, G. A., Pelham, W. E., Waschbusch, D. A., Gnagy, E. M., Lahey, B. B., Chronis, A. M., ... Burrows-Maclean, L. (2006). A practical measure of impairment:

Psychometric properties of the impairment rating scale in samples of children with attention deficit hyperactivity disorder and two school-based samples. Journal of Clinical Child and Adolescent Psychology, 35, 369-385. https://doi.org/10.1207/s15374424jccp3503_3

Fiorillo, C. D., Newsome, W. T., \& Schultz, W. (2008). The temporal precision of reward prediction in dopamine neurons. Nature Neuroscience, 11(8), 966-973.

Frank, M. J., O’Reilly, R. C., \& Seeberger, L. C. (2004). By carrot or by stick: cognitive reinforcement learning in parkinsonism. Science (New York, N.Y.), 306(5703), 19401943. https://doi.org/10.1126/science.1102941

Frank, M. J. (2005). Dynamic dopamine modulation in the basal ganglia: a neurocomputational account of cognitive deficits in medicated and nonmedicated Parkinsonism. Journal of Cognitive Neuroscience, 17(1), 51-72. https://doi.org/10.1162/0898929052880093

Frank, M. J., Santamaria, A., O’Reilly, R. C., \& Willcutt, E. (2007). Testing Computational Models of Dopamine and Noradrenaline Dysfunction in Attention Deficit/Hyperactivity Disorder. Neuropsychopharmacology, 32(7), 1583-1599. https://doi.org/10.1038/sj.npp.1301278

Gordon, C. T., \& Fabiano, G. A. (2019). The Transition of Youth with ADHD into the Workforce: Review and Future Directions. In Clinical Child and Family Psychology Review (Vol. 0). https://doi.org/10.1007/s10567-019-00274-4

Greenhill, L. L. (2002). Stimulant medication treatment of children with attention deficit hyperactivity disorder. In P.S. Jensen \& J. R. Cooper (Eds.), Attention deficit hyperactivity disorder: State of the science-best practices. (pp. 9-1-9-27). Kingston, NJ: Civic Research Institute.

Groen, Y., Mulder, L. J. M., Wijers, A. A., Minderaa, R. B., \& Althaus, M. (2009). Methylphenidate improves diminished error and feedback sensitivity in ADHD : An Evoked Heart Rate analysis. 82, 45-53. https://doi.org/10.1016/j.biopsycho.2009.05.004

Hayes, A. F. (2006). A primer on multilevel modeling. Human Communication Research, 32(4), 385-410. https://doi.org/10.1111/j.1468-2958.2006.00281.x

Hechtman, L., Sibley, M. H., Stehli, A., Owens, E. B., Mitchell, J. T., Arnold, L. E., ... Jensen, P. S. (2016). Functional Adult Outcomes 16 Years After Childhood Diagnosis of Attention-Deficit/Hyperactivity Disorder. J Am Acad Child Adolesc Psychiatry, 55(11), 945-952. https://doi.org/10.1007/978-3-319-46720-7 
Hoza, B., Gerdes, A. C., Mrug, S., Hinshaw, S. P., Bukowski, W. M., Gold, J. A., ... Wigal, T. (2005). Peer-assessed outcomes in the multimodal treatment study of children with attention deficit hyperactivity disorder. Journal of Clinical Child and Adolescent Psychology, 34, 74-86. https://doi.org/10.1207/s15374424jccp3401_7

Iwata, B. A., \& Bailey, J. S. (1974). Reward versus cost token systems: an analysis of the effects on students and teacher. Journal of the Applied Behavior Analysis, 7(4), 567-576. https://doi.org/10.1901/jaba.1974.7-567

Jensen, Peter S, Arnold, L. E., Swanson, J. M., Vitiello, B., \& Abikoff, H. B. (2007). 3year follow-up of the NIMH MTA study. Journal of the American Academy of Child \& Adolescent Psychiatry, 46, 989-1002. https://doi.org/10.1097/chi.0b013e3180686d48

Johansen, E. B., Sagvolden, T., Aase, H., \& Russell, V. A. (2005). The dynamic developmental theory of attention-deficit/hyperactivity disorder (ADHD): Present status and future perspectives. Behavioral and Brain Sciences, 28(3), 451-468. https://doi.org/10.1017/S0140525X05430071

Kaminski, J. W., Valle, L. A., Filene, J. H., \& Boyle, C. L. (2008). A meta-analytic review of components associated with parent training program effectiveness. Journal of Abnormal Child Psychology, 36(4), 567-589. https://doi.org/10.1007/s10802-007-9201-9

Kasper, L. J., Alderson, R. M., \& Hudec, K. L. (2012). Moderators of working memory deficits in children with attention-deficit/hyperactivity disorder (ADHD): A meta-analytic review. Clinical Psychology Review, 32(7), 605-617.

https://doi.org/10.1016/j.cpr.2012.07.001

Kaufman, K. F., \& O’Leary, K. D. (1972). Reward, Cost, and Self-Evaluation Procedures for Disruptive Adolescents in a Psychiatric Hospital School. Journal of Applie, 5(3), 293-309.

Kolko, D. J., Lindhiem, O., Hart, J., \& Bukstein, O. G. (2014). Evaluation of a booster intervention three years after acute treatment for early-onset disruptive behavior disorders. Journal of Abnormal Child Psychology, 42(3), 383-398. https://doi.org/10.1007/s10802-013-9724-1

Kortekaas-Rijlaarsdam, A. F., Luman, M., Sonuga-Barke, E., \& Oosterlaan, J. (2019). Does methylphenidate improve academic performance? A systematic review and metaanalysis. European Child and Adolescent Psychiatry, 28(2), 155-164. https://doi.org/10.1007/s00787-018-1106-3

Krause, K.-H., Dresel, S. H., Krause, J., Kung, H. F., \& Tatsch, K. (2000). Increased striatal dopamine transporter in adult patients with attention deficit hyperactivity disorder: effects of methylphenidate as measured by single photon emission computed 
tomography. Neuroscience Letters, 285(2), 107-110. https://doi.org/10.1016/S03043940(00)01040-5

Kuriyan, A. B., Pelham, W. E., Molina, B. S. G., Waschbusch, D. A., Gnagy, E. M., Sibley, M. H., ... Kent, K. M. (2013). Young adult educational and vocational outcomes of children diagnosed with ADHD. Journal of Abnormal Child Psychology, 4l(1), 27-41. https://doi.org/10.1007/s10802-012-9658-z

Macphee, F. L., Altszuler, A. R., Merrill, B. M., \& Pelham, W. E. (2017). Improving Daily Life Functioning of Children with ADHD; Medication, Behavioral Intervention, or Their Combination - “Just Say Yes to Drugs?” Redux. The Clinical Psychologist, 70(1), 5-14.

Massetti, G. M., Lahey, B. B., Pelham, W. E., Loney, J., Ehrhardt, A., Lee, S. S., \& Kipp, H. (2008). Academic achievement over 8 years among children who met modified criteria for attention-deficit/hyperactivity disorder at 4-6 years of age. Journal of Abnormal Child Psychology, 36(3), 399-410. https://doi.org/10.1007/s10802-007-9186-4

Mattfeld, A. T., Gluck, M. A., \& Stark, C. E. (2011). Functional specialization within the striatum along both the dorsal/ventral and anterior/posterior axes during associative learning via reward and punishment. Learn Mem, 18(11), 703-711.

https://doi.org/10.1101/lm.022889.111

McCarthy, S., Asherson, P., Coghill, D., Hollis, C., Murray, M., Potts, L., ... Wong, I. C. K. (2009). Attention-deficit hyperactivity disorder: Treatment discontinuation in adolescents and young adults. The British Journal of Psychiatry, 194(3), 273-277. https://doi.org/10.1192/bjp.bp.107.045245

McGoey, K. E., \& DuPaul, G. J. (2000). Token reinforcement and response cost procedures: Reducing the disruptive behavior of preschool children with attentiondeficit/hyperactivity disorder. School Psychology Quarterly, 15(3), 330-343. https://doi.org/10.1037/h0088790

Merrill, B. M., Molina, B. S. G., Coxe, S., Gnagy, E. M., Altszuler, A. R., Macphee, F. L., ... Pelham, W. E. (2019). Functional Outcomes of Young Adults with Childhood ADHD: A Latent Profile Analysis. Journal of Clinical Child and Adolescent Psychology, OO(00), 1-14. https://doi.org/10.1080/15374416.2018.1547968

Milich, R. (1994). The Response of Children with ADHD to Failure: If at First You Don’t Succeed, Do You Try, Try Again? School Psychology Review, 23(1), 11-28.

Milich, R., Carlson, C. L., Pelham, W. E., \& Licht, B. G. (1991). Effects of methylphenidate on the persistence of ADHD boys following failure experiences. Journal of Abnormal Child Psychology, 19, 519-536. 
Milich, R., \& Okazaki, M. (1991). An examination of learned helplessness among attention-deficit hyperactivity disordered boys. Journal of Abnormal Child Psychology, 19(5), 607-623. https://doi.org/10.1007/BF00925823

Molina, B. S. G., Hinshaw, S. P., Swanson, J. M., Arnold, L. E., Vitiello, B., Jensen, P. S., ... Houck, P. R. (2009). The MTA at 8 years: prospective follow-up of children treated for combined-type ADHD in a multisite study. Journal of the American Academy of Child and Adolescent Psychiatry, 48(5), 484-500.

https://doi.org/10.1097/CHI.0b013e31819c23d0

Molina, B. S. G., \& Pelham, W. E. (2014). Attention-deficit/hyperactivity disorder and risk of substance use disorder: developmental considerations, potential pathways, and opportunities for research. Annual Review of Clinical Psychology, 10, 607-639. https://doi.org/10.1146/annurev-clinpsy-032813-153722

Molina, B. S. G., Pelham, W. E., Cheong, J., Marshal, M. P., Gnagy, E. M., \& Curran, P. J. (2012). Childhood attention-deficit/hyperactivity disorder (ADHD) and growth in adolescent alcohol use: the roles of functional impairments, ADHD symptom persistence, and parental knowledge. Journal of Abnormal Psychology, 121(4), 922-935. https://doi.org/10.1037/a0028260

MTA Cooperative Group. (1999). A 14-Month Randomized Clinical Trial of Treatment Strategies for Attention-Deficit/ Hyperactivity Disorder. Archives of General Psychiatry, $56,1073-1086$.

MTA Cooperative Group. (2004). National Institute of Mental Health Multimodal Treatment Study of ADHD follow-up: 24-month outcomes of treatment strategies for attention-deficit/hyperactivity disorder. Pediatrics, 113(4), 754-761. Retrieved from http://www.ncbi.nlm.nih.gov/pubmed/15060224

Musser, E. D., Karalunas, S. L., Dieckmann, N., Peris, T. S., \& Nigg, J. T. (2017). Attention-Deficit/Hyperactivity DIsorder Developmental Trajectories related to Parental Expressed Emotion. Journal of Abnormal Psychology, 125(2), 182-195. https://doi.org/10.1183/09031936.00063810.

Page, T. F., Pelham III, W. E., Fabiano, G. A., Greiner, A. R., Gnagy, E. M., Hart, K. C., ... Pelham Jr., W. E. (2016). Comparative cost analysis of sequential, adaptive, behavioral, pharmacological, and combined treatments for childhood ADHD. Journal of Clinical Child \& Adolescent Psychology, O(0), 1-12.

https://doi.org/10.1080/15374416.2015.1055859

Patterson, G. R. (2002). The Early Development of Coercive Family Process. In J. B. Reid, G. R. Patterson, \& J. Snyder (Eds.), Antisocial Behavior in Children and Adolescents: A Developmental Analysis and Model for Intervention (pp. 25-44). Washington, D.C. 
Pelham Jr., W. E. (2008). Against the grain: A proposal for a psychosocial-first approach to treating ADHD - the Buffalo treatment algorithm. In K. McBurnett \& L. Pfiffner (Eds.), Attention Deficit/Hyperactivity Disorder: Concepts, Controversies, New Directions (pp. 301-316). New York: Informa Healthcare.

Pelham, W. E. (1993). Pharmacotherapy for children with attention-deficit hyperactivity disorder. School Psychology Review, 22, 199-227.

Pelham, W. E., Gnagy, E. M., Greenslade, K. E., \& Milich, R. (1992). Teacher ratings of DSM-III-R symptoms for the disruptive behavior disorders. Journal of the American Academy of Child \& Adolescent Psychiatry, 31, 210-218.

Pelham Jr., W. E., Gnagy, E. M., Greiner, A. R., Waschbusch, D. A., Fabiano, G. A., \& Burrows-Maclean, L. (2010). Summer treatment programs for attentiondeficit/hyperactivity disorder. In J. R. Weisz \& A. E. Kazdin (Eds.), Evidence-Based Psychotherapies for Children and Adolescents (2nd ed., pp. 277-292). New York: Guilford Press.

Pelham, W. E., Gnagy, E. M., Chronis, A. M., Burrows-MacLean, L., Fabiano, G. A., Onyango, A. N., ... Steiner, R. L. (1999). A comparison of morning-only and morning/late afternoon Adderall to morning-only, twice-daily, and three times-daily methylphenidate in children with attention-deficit/hyperactivity disorder. Pediatrics, 104, 1300-1311. Retrieved from http://www.ncbi.nlm.nih.gov/pubmed/10585981

Pelham, W. E., \& Bender, M. E. (1982). Peer relationships in hyperactive children: Description and treatment. In K. Gadow \& I. Bialer (Eds.), Advances in Learning and Behavioral Disabilities (pp. 365-436). Greenwich: JAI Press.

Pelham Jr., W. E., Fabiano, G. A., Waxmonsky, J. G., Greiner, A. R., Gnagy, E. M., Pelham III, W. E., ... Murphy, S. A. (2016). Treatment sequencing for childhood ADHD: A multiple-randomization study of adaptive medication and behavioral interventions. Journal of Clinical Child \& Adolescent Psychology, 0, 1-20. https://doi.org/10.1080/15374416.2015.1105138

Pelham, W. E., Hoza, B., Kipp, H. L., Gnagy, E. M., \& Trane, S. T. (1997). Effects of methylphenidate and expectancy on ADHD children's performance, self-evaluations, persistence, and attributions on a cognitive task. Experimental and Clinical Psychopharmacology, 5, 3-13. https://doi.org/10.1037/1064-1297.5.1.3

Pelham, W. E, Burrows-Maclean, L., Gnagy, E. M., Fabiano, G. A., Coles, E. K., Wymbs, B. T., ... Waschbusch, D. A. (2014). A dose-ranging study of behavioral and pharmacological treatment in social settings for children with ADHD. Journal of Abnormal Child Psychology, 42, 1019-1031. https://doi.org/10.1007/s10802-013-9843-8 
Pelham, W. E., \& Fabiano, G. A. (2008). Evidence-based psychosocial treatments for attention-deficit/hyperactivity disorder. Journal of Clinical Child and Adolescent Psychology, 37, 184-214. https://doi.org/10.1080/15374410701818681

Pelham, W. E., Fabiano, G. A., \& Massetti, G. M. (2005). Evidence-based assessment of attention deficit hyperactivity disorder in children and adolescents. Journal of Clinical Child and Adolescent Psychology, 34, 449-476.

https://doi.org/10.1207/s15374424jccp3403_5

Pelham, W. E., Gnagy, E. M., Burrows-Maclean, L., Williams, A., Fabiano, G. A., Morrisey, S. M., ... Morse, G. D. (2001). Once-a-day Concerta methylphenidate versus three-times-daily methylphenidate in laboratory and natural settings. Pediatrics, 107(6), E105. Retrieved from http://www.ncbi.nlm.nih.gov/pubmed/11389303

Pelham, W. E., Manos, M. J., Ezzell, C. E., Tresco, K. E., Gnagy, E. M., Hoffman, M. T., ... Morse, G. (2005). A dose-ranging study of a methylphenidate transdermal system in children with ADHD. Journal of the American Academy of Child and Adolescent Psychiatry, 44, 522-529. https://doi.org/10.1097/01.chi.0000157548.48960.95

Pfiffner, L. J., \& O’Leary, S. G. (1987). The efficacy of all-positive management as a function of the prior use of negative consequences. Journal of Applied Behavior Analysis, 20(3), 265-271.

Pliszka, S. (2007). Practice parameter for the assessment and treatment of children and adolescents with attention-deficit/hyperactivity disorder. Journal of the American Academy of Child and Adolescent Psychiatry, 46(7), 894-921. https://doi.org/10.1097/chi.0b013e318054e724

Prasad, V., Brogan, E., Mulvaney, C., Grainge, M., Stanton, W., \& Sayal, K. (2013). How effective are drug treatments for children with ADHD at improving on-task behaviour and academic achievement in the school classroom? A systematic review and meta-analysis. European Child \& Adolescent Psychiatry, 22(4), 203-216. https://doi.org/10.1007/s00787-012-0346-X

Preacher, K. J., Curran, P. J., \& Bauer, D. J. (2006). Computational Tools for Probing Interactions in Multiple Linear Regression, Multilevel Modeling, and Latent Curve Analysis. Journal of Educational and Behavioral Statistics, 31(4), 437-448. https://doi.org/10.3102/10769986031004437

Research Units on Pediatric Psychopharmacology (RUPP) Autism Network. (2005). Randomized, controlled, crossover trial of methylphenidate in pervasive developmental disorders with hyperactivity. Archives of General Psychiatry Gen Psychiatry, 62, 12661274. https://doi.org/10.1001/archpsyc.62.11.1266 
Rosch, K. S., Fosco, W. D., Pelham, W. E., Waxmonsky, J. G., Bubnik, M. G., \& Hawk, L. W. (2015). Reinforcement and Stimulant Medication Ameliorate Deficient Response Inhibition in Children with Attention-Deficit/Hyperactivity Disorder. Journal of Abnormal Child Psychology. https://doi.org/10.1007/s10802-015-0031-x

Rosen, L. A., O’Leary, S. G., Joyce, S. A., Conway, G., \& Pfiffner, L. J. (1984). The importance of prudent negative consequences for maintaining the appropriate behavior of hyperactive students. Journal of Abnormal Child Psychology, 12(4), 581-604. https://doi.org/10.1007/BF00916852

Schatz, N. K., Fabiano, G. A., Cunningham, C. E., dosReis, S., Waschbusch, D. A., Jerome, S., ... Morris, K. L. (2015). Systematic Review of Patients' and Parents' Preferences for ADHD Treatment Options and Processes of Care. Patient, 8(6), 483-497. https://doi.org/10.1007/s40271-015-0112-5

Schiffer, W. K., Volkow, N. D., Fowler, J. S., Alexoff, D. L., Logan, J., \& Dewey, S. L. (2006). Therapeutic doses of amphetamine or methylphenidate differentially increase synaptic and extracellular dopamine. Synapse, 59(4), 243-251.

https://doi.org/10.1002/syn.20235

Schultz, W. (1998). Predictive reward signal of dopamine neurons. Journal of Neurophysiology, 80(1), 1-27. https://doi.org/10.1007/s00429-010-0262-0

Shaffer, D. (2000). NIMH diagnostic interview schedule for children version IV (NIMHDISC-IV): Description, differences from previous versions, and reliability of some diagnoses. Journal of the American Academy of Child and Adolescent Psychiatry, 39, $28-38$.

Sibley, M. H., Pelham, W. E., Molina, B. S. G., Gnagy, E. M., Waschbusch, D. A., Biswas, A., ... Karch, K. M. (2011). The delinquency outcomes of boys with ADHD with and without comorbidity. Journal of Abnormal Child Psychology, 39(1), 21-32. https://doi.org/10.1007/s10802-010-9443-9

Strand, M. T., Hawk, L. W., Bubnik, M., Shiels, K., Pelham, W. E., \& Waxmonsky, J. G. (2012). Improving working memory in children with attention-deficit/hyperactivity disorder: The separate and combined effects of incentives and stimulant medication. Journal of Abnormal Child Psychology, 40(7), 1193-1207.

https://doi.org/10.1007/s10802-012-9627-6

Sullivan, M. A., \& O’Leary, S. G. (1990). Maintenance following reward and cost token programs. Behavior Therapy, 21(1), 139-149. https://doi.org/10.1016/S00057894(05)80195-9

Swanson, J. M., Wigal, S. B., Wigal, T., Sonuga-Barke, E., Greenhill, L., Biederman, J., ... Group, C. S. (2004). Development of a New Once-a-Day Formulation of 
Methylphenidate for the Treatment of Attention-deficit/Hyperactivity Disorder. Pediatrics, 113(3), 206-216.

Tamm, L., Denton, C. A., Epstein, J. N., Schatschneider, C., Taylor, H., Arnold, L. E., ... Vaughn, A. (2017). Comparing treatments for children with ADHD and word reading difficulties: A randomized clinical trial. Journal of Consulting and Clinical Psychology, 85(5), 434-446. https://doi.org/10.1037/ccp0000170

Ungless, M. A., Magill, P. J., \& Bolam, P. (2004). Uniform inhibition of dopamine neurons in the ventral tegmental area by aversive stimuli. Science, 303, 2040-2042.

Volkow, N. D., Wang, G. J., Tomasi, D., Kollins, S. H., Wigal, T. L., Newcorn, J. H., ... Swanson, J. M. (2012). Methylphenidate-elicited dopamine increases in ventral striatum are associated with long-term symptom improvement in adults with attention deficit hyperactivity disorder. Journal of Neuroscience, 32(3), 841-849.

https://doi.org/10.1523/JNEUROSCI.4461-11.2012

Volkow, N. D., Wang, G., Fowler, J. S., Logan, J., Gerasimov, M., Maynard, L., ... Franceschi, D. (2001). Therapeutic doses of oral methylphenidate significantly increase extracellular dopamine in the human brain. The Journal of Neuroscience: The Official Journal of the Society for Neuroscience, 21(2), RC121. https://doi.org/20014896 [pii]

Volkow, N. D, Wang, G. J., \& Baler, R. D. (2011). Reward, dopamine and the control of food intake: implications for obesity. Trends in Cognitive Sciences, 15(1), 37-46. https://doi.org/10.1016/j.tics.2010.11.001

Volkow, N. D, Wang, G.-J., Newcorn, J., Telang, F., Solanto, M. V, Fowler, J. S., ... Swanson, J. M. (2007). Depressed dopamine activity in caudate and preliminary evidence of limbic involvement in adults with attention-deficit/hyperactivity disorder. Archives of General Psychiatry, 64(8), 932-940. https://doi.org/10.1001/archpsyc.64.8.932

Waschbusch, D. A., Cunningham, C. E., Pelham, W. E., Rimas, H. L., Greiner, A. R., Gnagy, E. M., ... Hoffman, M. T. (2011). A discrete choice conjoint experiment to evaluate parent preferences for treatment of young, medication naive children with ADHD. Journal of Clinical Child and Adolescent Psychology, 40(4), 546-561. https://doi.org/10.1080/15374416.2011.581617

Waxmonsky, J. G., Waschbusch, D. A., Belin, P., Li, T., Babocsai, L., Humphery, H., ... Pelham, W. E. (2016). A Randomized Clinical Trial of an Integrative Group Therapy for Children with Severe Mood Dysregulation. Journal of the American Academy of Child and Adolescent Psychiatry, 55(3), 196-207. https://doi.org/10.1016/j.jaac.2015.12.011

Wells, K. C., Chi, T. C., Hinshaw, S. P., Epstein, J. N., Pfiffner, L., Nebel-Schwalm, M., ... Wigal, T. (2006). Treatment-related changes in objectively measured parenting behaviors in the multimodal treatment study of children with attention- 
deficit/hyperactivity disorder. Journal of Consulting and Clinical Psychology, 74(4), 649-657. https://doi.org/10.1037/0022-006X.74.4.649

Whalen, C. K., \& Henker, B. (1991). Social Impact of Stimulant Treatment for Hyperactive Children. Journal of Learning Disabilities, 24(4), 231-241.

Wolraich, M., Brown, L., Brown, R. T., DuPaul, G., Earls, M., Feldman, H. M., ... Visser, S. (2011). ADHD: clinical practice guideline for the diagnosis, evaluation, and treatment of attention-deficit/hyperactivity disorder in children and adolescents.

Pediatrics, 128(5), 1007-1022. https://doi.org/10.1542/peds.2011-2654 
Table 1

Sample Characteristics

\begin{tabular}{ll}
\hline Age $M$ (SD) & $8.72(1.70)$ \\
Gender (\% Male) & 77.8 \\
Ethnicity (\%) & 81.5 \\
$\quad$ Hispanic & 14.8 \\
Non-Hispanic & 3.7 \\
$\quad$ Did not respond & \\
Race (\%) & 77.8 \\
$\quad$ White & 14.8 \\
African American & 7.4 \\
Multi-racial & \\
Highest Parental Education (\%) & 3.7 \\
$\quad$ Less than high school & 14.8 \\
$\quad$ High school or GED & 7.4 \\
$\quad$ Partial college & 14.8 \\
$\quad$ Associate's degree & 33.3 \\
$\quad$ Bachelor's degree & 25.9 \\
$\quad$ Graduate training or degree & $96.81(13.02)$ \\
Estimated Full-Scale IQ $M$ (SD) & 88.9 \\
ODD Diagnosis (\%) & $0.85(0.91)$ \\
CD Symptoms $M$ (SD)
\end{tabular}

Note. $\mathrm{n}=27$ 
Table 2

Sample Participant Testing Schedule

\begin{tabular}{lll}
\hline Day & Medication & Punishment Condition \\
\hline 1 & Placebo & Enhanced \\
2 & $0.3 \mathrm{mg} / \mathrm{kg} \mathrm{MPH}$ & Regular \\
3 & $0.15 \mathrm{mg} / \mathrm{kg} \mathrm{MPH}$ & Enhanced \\
4 & Placebo & Regular \\
5 & $0.6 \mathrm{mg} / \mathrm{kg} \mathrm{MPH}$ & Enhanced \\
6 & $0.15 \mathrm{mg} / \mathrm{kg} \mathrm{MPH}$ & Regular \\
7 & $0.6 \mathrm{mg} / \mathrm{kg} \mathrm{MPH}$ & Regular \\
8 & $0.3 \mathrm{mg} / \mathrm{kg} \mathrm{MPH}$ & Enhanced \\
\hline
\end{tabular}

Note. $\mathrm{MPH}=$ Methylphenidate 
Table 3

Task Structure by Trial Type and Punishment Condition

\begin{tabular}{llll}
\hline RP Condition & Probability "A" (\%) & Probability "B" (\%) & Trial Type \\
\hline Image 1 & 80 & 20 & Reward \\
Image 2 & 20 & 80 & Reward \\
Image 3 & 80 & 20 & Punishment (Regular) \\
Image 4 & 20 & 80 & Punishment (Regular) \\
\hline EP Condition & Probability "A" (\%) & Probability "B" (\%) & Trial Type \\
\hline Image 1 & 80 & 20 & Reward \\
Image 2 & 20 & 80 & Reward \\
Image 3 & 80 & 20 & Punishment (Enhanced) \\
Image 4 & 20 & 80 & Punishment (Enhanced) \\
\hline
\end{tabular}

Note. $R P=$ Regular Punishment, $E P=$ Enhanced Punishment. 
Table 4

Raw Means and Standard Deviations for Dependent Measures

\begin{tabular}{lccccc}
\hline \multirow{2}{*}{ Outcome } & $\begin{array}{c}\text { Punishment } \\
\text { Condition }\end{array}$ & $\begin{array}{c}\text { Placebo } \\
M(S D)\end{array}$ & $0.15 \mathrm{mg} / \mathrm{kg} \mathrm{MPH}$ & $0.3 \mathrm{mg} / \mathrm{kg} \mathrm{MPH}$ & $0.6 \mathrm{mg} / \mathrm{kg} \mathrm{MPH}$ \\
Reward trial performance & RP & $0.59(0.23)$ & $0.62(0.21)$ & $0.63(0.21)$ & $0.64(0.22)$ \\
& EP & $0.55(0.22)$ & $0.58(0.20)$ & $0.64(0.22)$ & $0.63(0.18)$ \\
Punishment trial performance & RP & $0.56(0.15)$ & $0.58(0.12)$ & $0.57(0.19)$ & $0.57(0.18)$ \\
& EP & $0.57(0.17)$ & $0.57(0.15)$ & $0.56(0.14)$ & $0.56(0.16)$
\end{tabular}

Note. $R P=$ Regular Punishment, $E P=$ Enhanced Punishment. Models were conducted on estimated marginal means. Raw means and standard deviations are presented for ease of interpretation. Means represent the average percentage of correct stimuli-category associations per session. 
Table 5

Results of Multilevel Model for Task Performance

\begin{tabular}{llllll}
\hline Term & Estimate & $S E$ & $\mathrm{t}$ & $p$ & $95 \%$ CI \\
\hline Intercept & 0.62 & 0.03 & 22.13 & $<0.001$ & $0.56,0.67$ \\
Punishment Trial Type (vs. Reward) & -0.13 & 0.03 & -4.04 & $<0.001$ & $-0.19,-0.06$ \\
EP Condition (vs. RP) & -0.09 & 0.02 & -3.26 & $<0.01$ & $-0.13,-0.03$ \\
$0.15 \mathrm{mg} / \mathrm{kg}$ MPH (vs. Placebo) & 0.02 & 0.02 & 0.95 & $\mathrm{~ns}$ & $-0.03,0.07$ \\
$0.3 \mathrm{mg} / \mathrm{kg}$ MPH (vs. Placebo) & -0.02 & 0.02 & -0.74 & $\mathrm{~ns}$ & $-0.07,0.03$ \\
$0.6 \mathrm{mg} / \mathrm{kg}$ MPH (vs. Placebo) & 0.01 & 0.03 & 0.16 & $\mathrm{~ns}$ & $-0.05,0.05$ \\
Punishment Trial*EP Condition & 0.09 & 0.03 & 2.66 & $<0.01$ & $0.02,0.16$ \\
Punishment Trial*0.15 mg/kg MPH & -0.01 & 0.03 & -0.27 & $\mathrm{~ns}$ & $-0.08,0.06$ \\
Punishment Trial*0.3 mg/kg MPH & 0.04 & 0.03 & 1.04 & $\mathrm{~ns}$ & $-0.03,0.10$ \\
Punishment Trial*0.6 mg/kg MPH & -0.01 & 0.04 & -0.01 & $\mathrm{~ns}$ & $-0.07,0.07$ \\
EP Condition*0.15 mg/kg MPH & 0.01 & 0.03 & 0.04 & $\mathrm{~ns}$ & $-0.07,0.07$ \\
EP Condition*0.3 mg/kg MPH & 0.11 & 0.03 & 3.17 & $<0.01$ & $0.04,0.18$ \\
EP Condition*0.6 mg/kg MPH & 0.06 & 0.04 & 1.79 & $<0.10$ & $-0.01,0.13$ \\
Punishment Trial* EP Condition*0.15 mg/kg MPH & -0.01 & 0.05 & -0.16 & $\mathrm{~ns}$ & $-0.10,0.09$ \\
Punishment Trial*EP Condition*0.3 mg/kg MPH & -0.13 & 0.05 & -2.65 & $<0.01$ & $-0.22,-0.03$ \\
Punishment Trial*EP Condition*0.6 mg/kg MPH & -0.08 & 0.05 & -1.72 & $<0.10$ & $-0.18,0.01$ \\
Block & 0.01 & 0.01 & 1.09 & $\mathrm{~ns}$ & $-0.01,0.02$ \\
Punishment Trial*Block & 0.02 & 0.01 & 2.42 & $<0.05$ & $0.01,0.03$
\end{tabular}

Note. $S E=$ standard error. $E P=$ Enhanced Punishment. $R P=$ Regular Punishment. All binary variables were coded as dummy variables (e.g., Punishment Trial $=0$, Reward Trial $=1$ ). 
Figure 1

Task Feedback by Trial Type and Punishment Condition

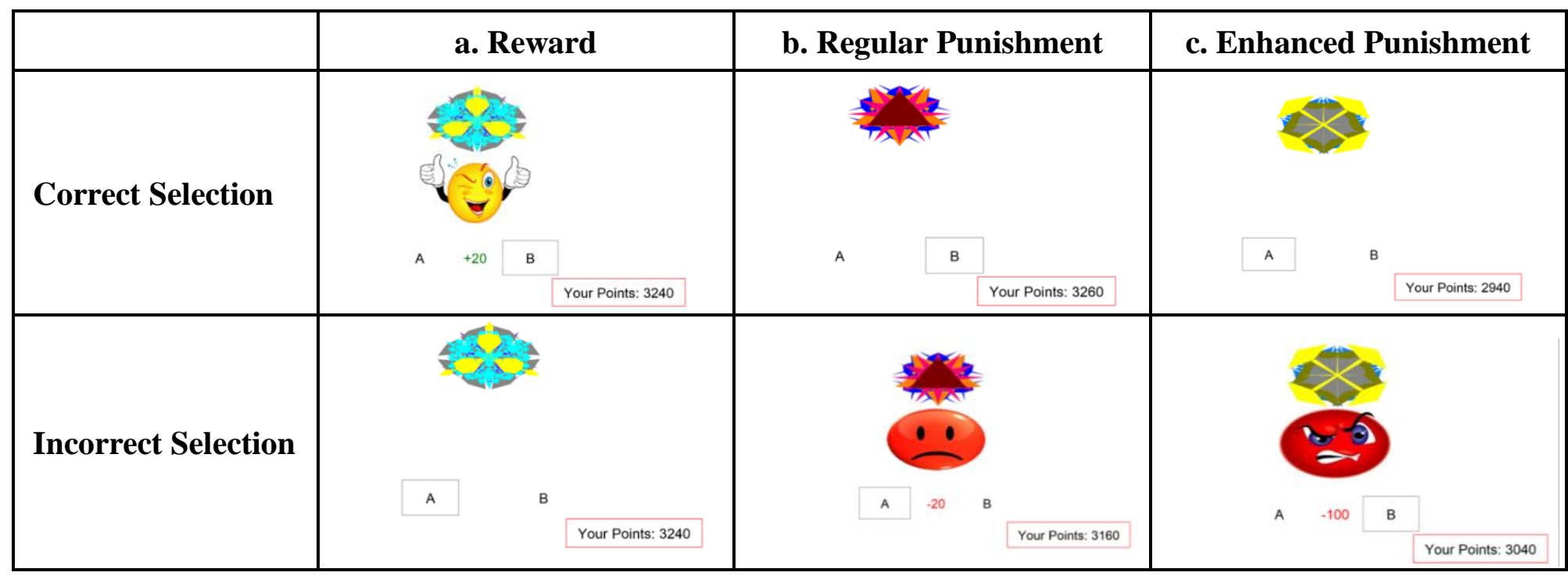

Note. Accurate feedback is depicted for demonstration purposes. Sample image for Reward and Regular Punishment trials belonged to Category "B." Sample image for Enhanced Punishment trials belonged to Category "A." 
Figure 2

Task Learning by Punishment Condition and Trial Type

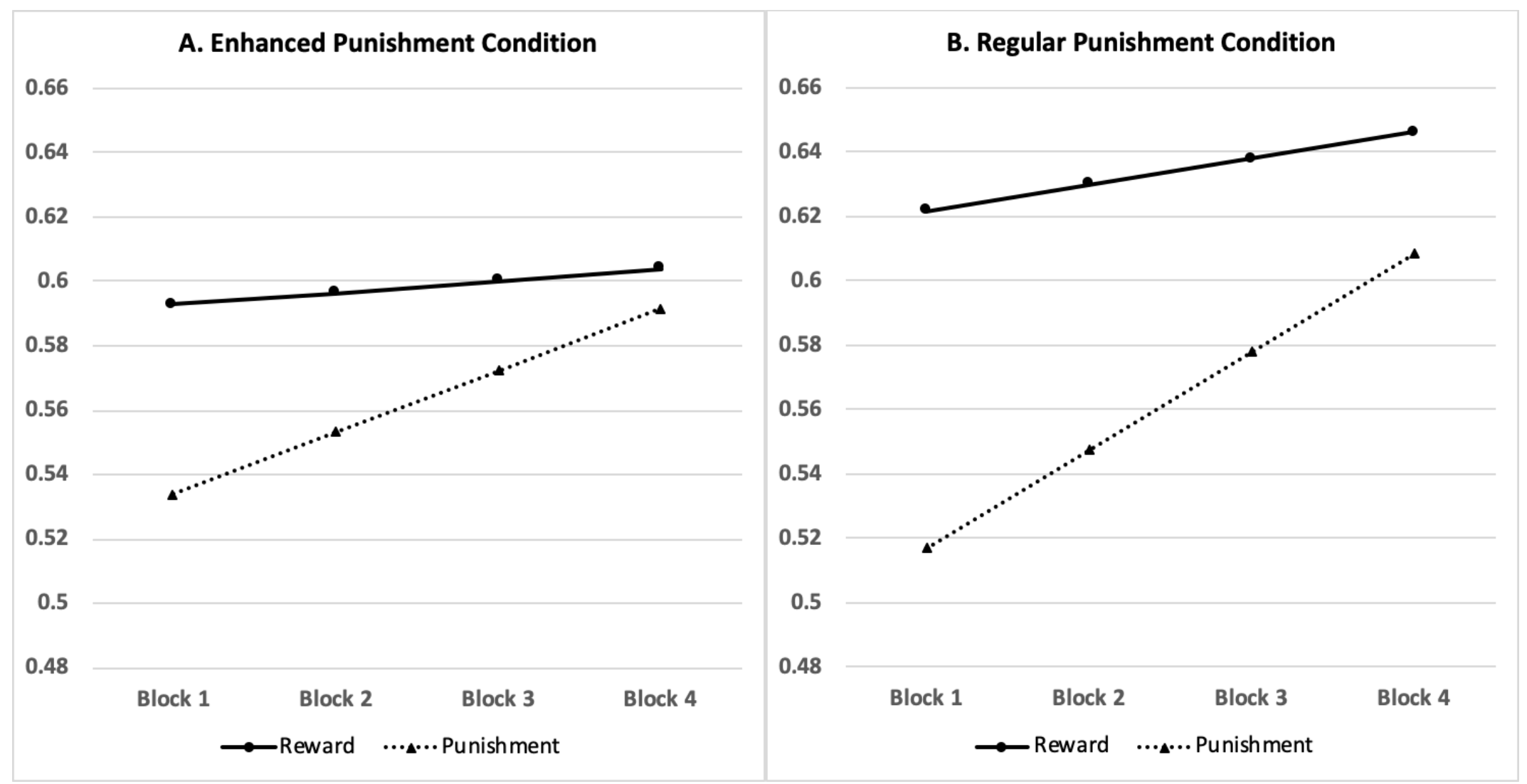

Note. Task performance is measured by the percentage of correct stimuli-category associations per testing session. 
Figure 3

Task Performance by Trial Type, Punishment Condition, and Medication Dose

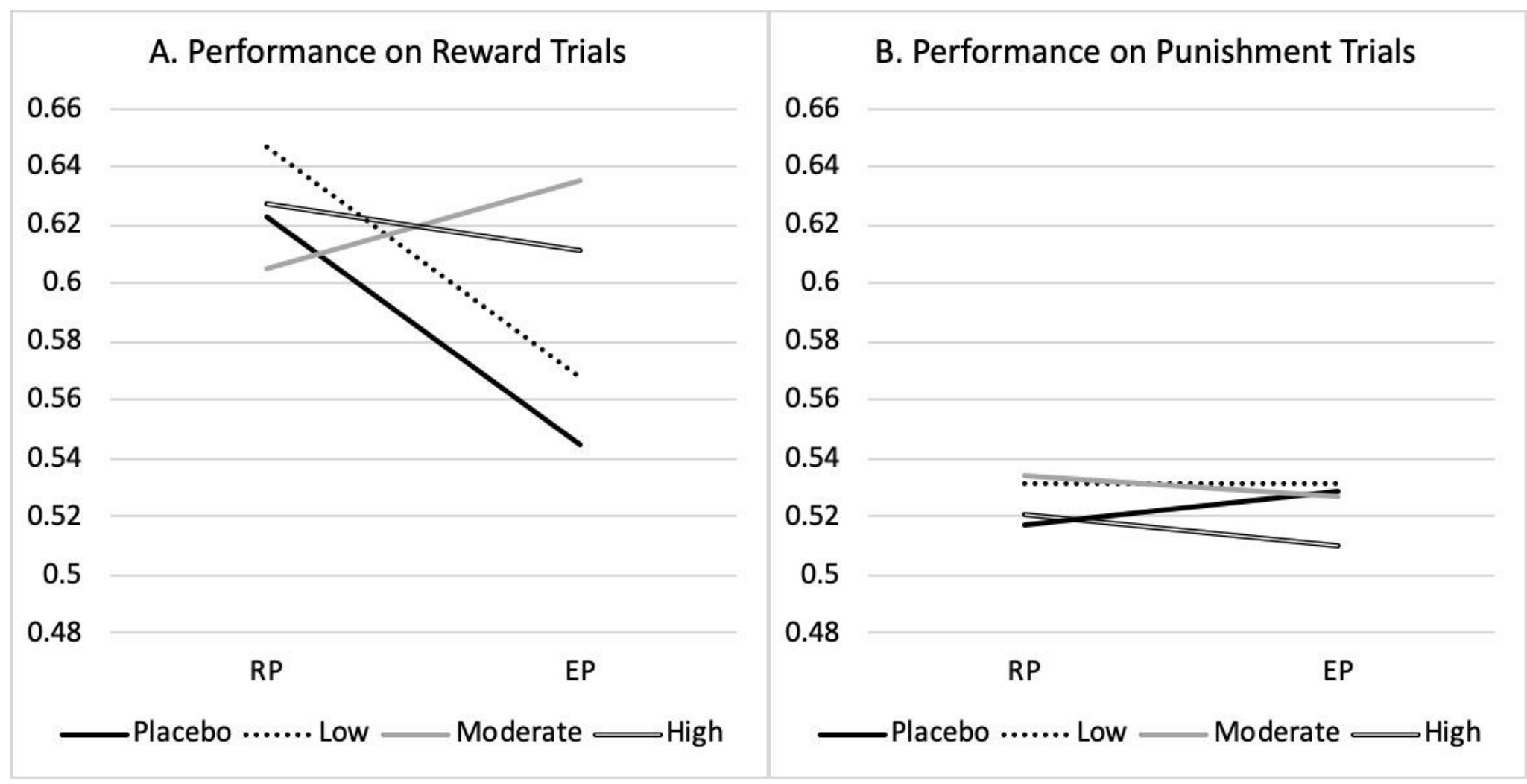

Note. $R P=$ Regular Punishment. EP= Enhanced Punishment. Task performance is measured by the percentage of correct stimuli-category associations per testing session. 
VITA

AMY R. ALTSZULER

2011

2015

2018

$2018-2019$
B.A., Psychology (cum laude, Departmental Honors) University of Miami

Coral Gables, Florida

M.S., Psychology

Florida International University

Miami, Florida

Predoctoral Internship (APA Accredited)

Kennedy Krieger Institute/The Johns Hopkins University School of Medicine

Baltimore, Maryland

Research Associate

Florida International University

Miami, Florida

\section{PUBLICATIONS}

Altszuler, A. R., Morrow, A. S., Merrill, B. M., Bressler, S., Macphee, F. L., Gnagy, E. M., Greiner, A. R., Coxe, S., Raiker, J. S., Coles, E. K., Pelham, W. E. (2017). The effect of stimulant medication and training on the sports competence of children with ADHD. Journal of Clinical Child and Adolescent Psychology, Advance Online Publication. DOI 10.1080/15374416.2016.1270829

Altszuler, A. R., Page, T. F., Gnagy, E. M., Coxe, S., Arrieta, A., Molina, B. S. G., Pelham, W. E. (2016). Financial dependence of young adults with ADHD. Journal of Abnormal Child Psychology, 44, 1217-1229, DOI 10.1007/s10802-015-0093-9.

Altszuler, A. R., Hupp, S., Pelham, W. E. (2018). Closing the research to practice gap. In S. Hupp (Ed.), Child and adolescent psychotherapy: Components of evidence-based treatments for youth and their parents. Cambridge University Press.

Altszuler, A. R., Macphee, F. L., Merrill, B. M., Morrow, A. S., Schatz, N. K., \& Pelham, W. E. (2017). Attention-deficit hyperactivity disorder. In C. Flessner \& J. Piacentini (Eds.), Clinical handbook of psychological disorders in children and adolescents: A stepby-step treatment manual. New York, NY: Guilford Press.

Altszuler, A. R. \& Pelham, W. E. (2017, August). Secrets for Maintaining the Gains of Behavioral Parent Training. ADDitude Online Magazine. Retrieved from:

https://www.additudemag.com/behavior-therapy-examples-common-setbacks-andsolutions/ 
Altszuler, A. R. \& Pelham, W. E. (2017, August). Scream-Free Parenting. ADDitude, $18(1), 62-65$.

Kuriyan, A. B., Altszuler, A. R., Comer, J. S. \& Pelham, W.E. (2017). Disseminating evidence-based practice for child and adolescent mental health: A web-based initiative. Evidence-based Practice in Child and Adolescent Mental Health, 2(1), 54-67, DOI: 10.1080/23794925.2017.1286958

Macphee, F. L., Altszuler, A. R., Merrill, B. M., \& Pelham, W. E. (2017). Improving daily life functioning of children with ADHD; "Just say yes to drugs?" redux. The Clinical Psychologist, 70(1), 5-14.

Macphee, F.L., Merrill, B. M., Altszuler, A. R., Morrow, A. S., Ramos, M. C., Gnagy, E. M., Greiner, A. R., Coxe S., Raiker, J. S., Coles, E. Pelham, W. E. (in press). The effect of weighted vests and stability balls in combination with and without psychostimulant medication on classroom outcomes in children with ADHD. School Psychology Review.

Merrill, B. M., Molina, B. S. G., Coxe, S., Gnagy, E. M., Altszuler, A. R., Macphee, F. L., Morrow, A. S., Truco, E. M., \& Pelham, W. E. (2019). Functional outcomes of young adults with childhood ADHD: A latent profile analysis. Journal of Clinical Child and Adolescent Psychology. DOI 10.1080/15374416.2018.1547968

Merrill, B. M., Morrow, A. S., Altszuler, A. R., Macphee, F. L., Gnagy, E. M., Greiner, A. R., Coles, E., Raiker, J., Coxe, S., \& Pelham Jr., W. E. (2016). Improving homework performance among children with ADHD: A randomized clinical trial. Journal of Consulting and Clinical Psychology, Advance Online Publication. DOI 10.1037/ccp0000144

Sibley, M. H., Altszuler, A. R., Morrow, A. S., \& Merrill, B. M. (2014). Mapping the academic problem behaviors of adolescents with ADHD. School Psychology Quarterly, 29(4), 422-437.

Sibley, M. H., Altszuler, A. R., Ross, J. M., Sanchez, F., Pelham, W. E., \& Gnagy, E. M. (2014). A group-based parent-teen collaborative intervention for high school students with ADHD. Cognitive and Behavioral Practice, 21, 32-42.

Waschbusch, D. A., Willoughby, M. T., Haas, S. M., Ridenour, T., Crum, K. I., Helseth, S. A., Altszuler, A. R., Ross, J. M., Coles, E. K., \& Pelham Jr., W. E. (in press, April 2019). Effects of behavioral treatment modified to fit children with conduct problems and callous-unemotional (CU) traits. Journal of Clinical Child and Adolescent Psychology.

Zhao, X., Page, T., Altszuler, A. R., Pelham, W. E. III, Kipp, H., Gnagy, E. M., Coxe, S., Schatz, N. K., Merrill, B. M., Macphee, F. L., Pelham, W. E. Jr. (2019). Family burden of raising a child with ADHD. Journal of Abnormal Child Psychology. DOI 10.1007/s 10802-019-00518-5 